\title{
Reference ranges for cardiac structure and function using cardiovascular magnetic resonance (CMR) in Caucasians from the UK Biobank population cohort
}

Steffen E. Petersen ${ }^{1 *}$, Nay Aung ${ }^{1}$, Mihir M. Sanghvi ${ }^{1}$, Filip Zemrak ${ }^{1}$, Kenneth Fung ${ }^{1}$, Jose Miguel Paiva ${ }^{1}$, Jane M. Francis ${ }^{2}$, Mohammed Y. Khanji ${ }^{1}$, Elena Lukaschuk ${ }^{2}$, Aaron M. Lee ${ }^{1}$, Valentina Carapella², Young Jin Kim²,3, Paul Leeson ${ }^{2}$, Stefan K. Piechnik ${ }^{2}$ and Stefan Neubauer ${ }^{2}$

\begin{abstract}
Background: Cardiovascular magnetic resonance (CMR) is the gold standard method for the assessment of cardiac structure and function. Reference ranges permit differentiation between normal and pathological states. To date, this study is the largest to provide CMR specific reference ranges for left ventricular, right ventricular, left atrial and right atrial structure and function derived from truly healthy Caucasian adults aged 45-74.

Methods: Five thousand sixty-five UK Biobank participants underwent CMR using steady-state free precession imaging at 1.5 Tesla. Manual analysis was performed for all four cardiac chambers. Participants with non-Caucasian ethnicity, known cardiovascular disease and other conditions known to affect cardiac chamber size and function were excluded. Remaining participants formed the healthy reference cohort; reference ranges were calculated and were stratified by gender and age $(45-54,55-64,65-74)$.
\end{abstract}

Results: After applying exclusion criteria, 804 (16.2\%) participants were available for analysis. Left ventricular (LV) volumes were larger in males compared to females for absolute and indexed values. With advancing age, LV volumes were mostly smaller in both sexes. LV ejection fraction was significantly greater in females compared to males (mean \pm standard deviation [SD] of $61 \pm 5 \%$ vs $58 \pm 5 \%$ ) and remained static with age for both genders. In older age groups, LV mass was lower in men, but remained virtually unchanged in women. LV mass was significantly higher in males compared to females (mean \pm SD of $53 \pm 9 \mathrm{~g} / \mathrm{m}^{2}$ vs $42 \pm 7 \mathrm{~g} / \mathrm{m}^{2}$ ). Right ventricular (RV) volumes were significantly larger in males compared to females for absolute and indexed values and were smaller with advancing age. RV ejection fraction was higher with increasing age in females only. Left atrial (LA) maximal volume and stroke volume were significantly larger in males compared to females for absolute values but not for indexed values. LA ejection fraction was similar for both sexes. Right atrial (RA) maximal volume was significantly larger in males for both absolute and indexed values, while RA ejection fraction was significantly higher in females.

Conclusions: We describe age- and sex-specific reference ranges for the left ventricle, right ventricle and atria in the largest validated normal Caucasian population.

Keywords: Cardiovascular magnetic resonance, Reference values, Ventricular function, Atrial function

\footnotetext{
* Correspondence: s.e.petersen@qmul.ac.uk

${ }^{1}$ William Harvey Research Institute, NIHR Cardiovascular Biomedical Research

Unit at Barts, Queen Mary University of London, Charterhouse Square,

London EC1M 6BQ, UK

Full list of author information is available at the end of the article
} 


\section{Background}

Quantitative assessment of the cardiac chambers is vital for the determination of pathological states in cardiovascular disease. Intrinsic to this is knowledge of reference values for morphological and functional cardiovascular parameters specific to cardiovascular magnetic resonance (CMR), the most advanced tool for imaging the human heart. CMR has rapidly evolved towards faster and more detailed imaging methods limiting the generalisability of earlier results from relatively small studies [1-4]. More recent studies detailing "normal" ranges for CMR are limited by inclusion of individuals with cardiovascular risk factors such as obesity, diabetes and current smokers in their reference cohort $[5,6]$.

The UK Biobank is amongst the world's largest population-based prospective studies, established to investigate the determinants of disease in middle and old age [7]. In addition to the collection of extensive baseline questionnaire data, biological samples and physical measurements, CMR is utilized to provide cardiovascular imaging-derived phenotypes [8].

Based on the UK Biobank participant demographics and health status in $\sim 5000$ consecutive participants from the early phase of CMR $[8,9]$, we aim to select validated normal healthy Caucasian participants in order to establish reference values for left ventricular, right ventricular, left atrial and right atrial structure and function.

\section{Methods}

\section{Study population}

CMR examinations of 5,065 consecutive UK Biobank participants were assessed. Participants with nonCaucasian ethnicity, known cardiovascular disease, hypertension, respiratory disease, diabetes mellitus, hyperlipidaemia, haematological disease, renal disease, rheumatological disease, malignancy, symptoms of chest pain or dyspnoea, current- or ex-tobacco smokers, those taking medication for diabetes, hyperlipidaemia or hypertension and those with BMI $\geq 30 \mathrm{~kg} / \mathrm{m}^{2}$ [10] were excluded from the analysis. In order to create evenly distributed age-decade groups (45-54, 55-64, 65-74), all participants older than 74 years were also excluded from the cohort. (See Appendix 1 for the full list of exclusions).

\section{CMR protocol}

The full CMR protocol in the UK Biobank has been described in detail elsewhere [9]. In brief, all CMR examinations were performed in Cheadle, United Kingdom, on a clinical wide bore 1.5 Tesla scanner (MAGNETOM Aera, Syngo Platform VD13A, Siemens Healthcare, Erlangen, Germany).
Assessment of cardiac function was performed based on combination of several cine series: long axis cines (horizontal long axis - HLA, vertical long axis - VLA, and left ventricular outflow tract -LVOT cines, both sagittal and coronal) and a complete short axis stack covering the left ventricle (LV) and right ventricle (RV) were acquired at one slice per breath hold. All acquisitions used balanced steady-state free precession (bSSFP) with typical parameters (subject to standard radiographer changes to planning), as follows: $\mathrm{TR} / \mathrm{TE}=2.6 .1 .1 \mathrm{~ms}$, flip angle $80^{\circ}$, Grappa factor 2 , voxel size $1.8 \mathrm{~mm} \times 1.8 \mathrm{~mm} \times 8 \mathrm{~mm}(6 \mathrm{~mm}$ for long axis). The actual temporal resolution of $32 \mathrm{~ms}$ was interpolated to 50 phases per cardiac cycle ( $20 \mathrm{~ms}$ ). No signal or image filtering was applied besides distortion correction.

\section{Image analysis}

Manual analysis of LV, RV, LA and RA were performed across two core laboratories based in London and Oxford, respectively. Standard operating procedures for analysis of each chamber were developed and approved prior to study commencement. CMR scans were analysed using $\mathrm{cvi}^{42}$ post-processing software (Version 5.1.1, Circle Cardiovascular Imaging Inc., Calgary, Canada).

In each CMR examination, the end-diastolic phase was selected as the first phase of the acquisition. Observers selected the end-systolic phase by determining the phase in which the LV intra-cavity blood pool was at its smallest by visual assessment at the midventricular level. LV endocardial and epicardial borders were manually traced in both the end-diastolic and end-systolic phases in the short-axis view. In both end-diastole and end-systole, the most basal slice for the LV was selected when at least $50 \%$ of the LV blood pool was surrounded by myocardium. In order to reduce observer variability, LV papillary muscles were included as part of LV end-diastolic volume and end-systolic volume, and excluded from LV mass. As an internal quality control measure, the LV mass values in both diastole and systole were checked to ensure they are almost identical. In cases with significant discrepancy, the contours were reviewed and corrected through consensus group approach.

For the RV, endocardial borders were manually traced in end-diastole and end-systole in the short axis view. Volumes below the pulmonary valve were included. At the inflow tract, thin-walled structures without trabeculations were not included as part of the RV. RV end-diastolic and end-systolic phases were denoted to be the same as those for the LV. LV and RV stroke volumes were checked to ensure they were similar. 
LA and RA end-diastolic volume, end-systolic volume, stroke volume and ejection fraction were derived by manually tracing endocardial LA contours at end-systole (maximal LA area) and end-diastole (minimal LA area) in the HLA (4-chamber) view. For LA, the same measurements were also derived from the VLA (2-chamber) view and LA volumes were calculated according to the biplane area-length method. Example contours for all four cardiac chambers are provided in Fig. 1.

\section{Inter-observer and inter-centre quality assurance aspects}

Image analysis was undertaken by a team of eight observers under guidance of three principal investigators. For all cases, analysts filled in progress sheets to monitor any problems in evaluation of CMR data, with any problematic cases flagged, such as a significant discrepancy (defined as more than 10\% difference). For such flagged cases all contours and images were reviewed looking for presence of artefacts or slice location problems, operator error or evidence of pathology, such as significant shunt or valve regurgitation. These cases were discussed in regular intercentre meetings by teleconferencing with respective decisions closed by consensus of at least three team members with relevant knowledge. The team included two biomedical engineers, one radiologist, two career image analysts and six cardiologists. The quality assessment outputs were subject to formal ontological analysis [11]. Inter- and intra-observer variability between analysts for atrial and ventricular measurements was assessed by analysis of fifty, randomlyselected CMR examinations, repeated after a onemonth interval.

\section{Statistical analysis}

All data is presented as mean \pm standard deviation unless stated otherwise. Continuous variables were visually assessed for normality using histograms and Q-Q plots. Independent sample Student's t-test was used to compare the mean values of CMR parameters between men and women. Outliers were defined $a$ priori as CMR measurements more than three
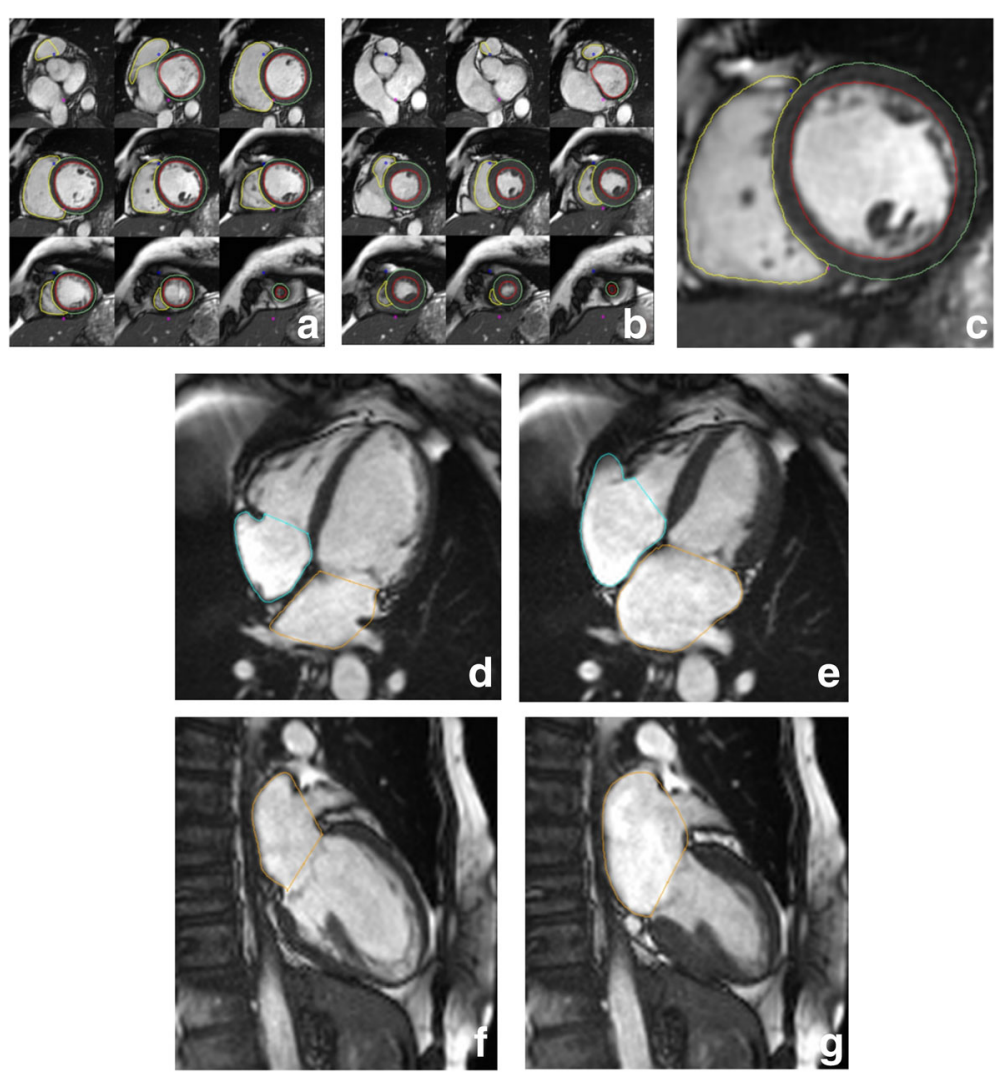

Fig. 1 Examples of ventricular and atrial contours. The above panels are representative of analysis undertaken on each CMR examination. $\mathbf{a}$ and $\mathbf{b}$ demonstrate contouring of the left and right ventricle from base to apex at end-diastole and end-systole, respectively. $\mathbf{d}$ and $\mathbf{e}$ demonstrate contouring of the left and right atrium in the four-chamber view. $\mathbf{f}$ and $\mathbf{g}$ demonstrate contouring of the left atrium in the two-chamber view 
interquartile ranges below the first quartile or above the third quartile and removed from analysis. Mean values for all cardiac parameters are presented by gender and decade (45-54, 55-64, 65-74). Reference ranges for measured (volume, mass) and derived (ejection fraction) data are defined as the $95 \%$ predic-

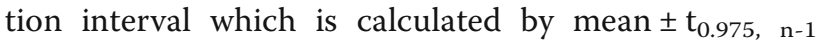
$(\sqrt{ }(\mathrm{n}+1) / \mathrm{n})$ (standard deviation) [12]. Absolute values were indexed to body surface area (BSA) using the DuBois and DuBois formula [13].

The normal ranges for the whole cohort (aged 4574) were defined as the range where the measured value fell within the $95 \%$ prediction interval for the whole cohort regardless of age decade. The borderline zone was defined as the upper and lower ranges where the measured value lay outside the $95 \%$ prediction interval for at least one age group. The abnormal zone was defined as the upper and lower ranges where the measured values were outside the $95 \%$ prediction interval for any age group.
Pearson's correlation coefficient was used to assess the impact of age on ventricular and atrial volumes and function. Intra-class correlation coefficients (ICC) were calculated to assess inter- and intra-observer variability, and were visually assessed using BlandAltman plots [14]. Two-way ICC $(2,1)$ was computed for inter-observer ICCs, to reflect the fact that a sample of cases and a sample of raters were observed, whilst a one-way ICC $(1,1)$ was computed for intraobserver ICC [15]. A $p$-value $<0.05$ was considered statistically significant for all tests performed. Statistical analysis was performed using $\mathrm{R}$ (version 3.3.0) Statistical Software [16].

\section{Results}

A total of 5,065 CMR examinations underwent manual image analysis. 90 subjects were excluded as either the CMR data was of insufficient quality or the CMR identifier did not match the participant identifier. Of the remaining 4,975, 804 (16.2\%) met the

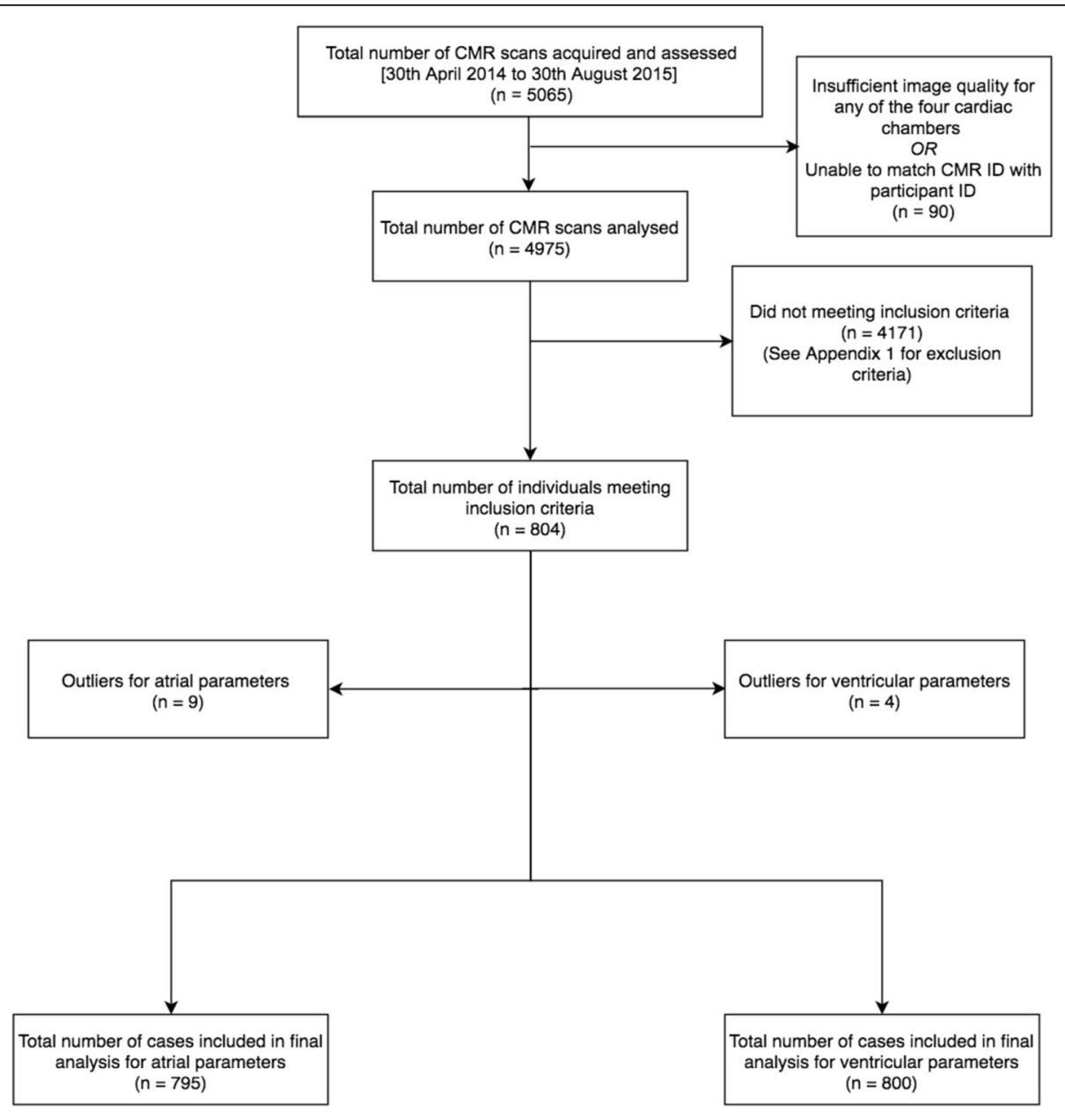

Fig. 2 Case selection flowchart 
Table 1 Baseline Characteristics

\begin{tabular}{llll}
\hline & \multicolumn{3}{c}{ Age groups (years) } \\
\cline { 2 - 4 } & $45-54$ & $55-64$ & 333 \\
Number of participants & 240 & $59( \pm 3)$ & $65-74$ \\
Age (years) & $51( \pm 2)$ & $159(47.7 \%)$ & $68( \pm 2)$ \\
Male gender $(\mathrm{n}(\%))$ & $110(45.8 \%)$ & $133( \pm 17)$ & $102(44.2 \%)$ \\
Systolic blood pressure $(\mathrm{mmHg})$ & $126( \pm 14)$ & $78( \pm 9)$ & $137( \pm 17)$ \\
Diastolic blood pressure $(\mathrm{mmHg})$ & $76( \pm 8)$ & $69( \pm 12)$ & $77( \pm 9)$ \\
Heart rate $(\mathrm{bpm})$ & $67( \pm 10)$ & $71( \pm 12)$ & $70( \pm 11)$ \\
Weight $(\mathrm{kg})$ & $71( \pm 13)$ & $170( \pm 9)$ & $169( \pm 11)$ \\
Height $(\mathrm{cm})$ & $171( \pm 9)$ & $1.82( \pm 0.19)$ & $1.78( \pm 0.18)$ \\
Body surface area $\left(\mathrm{m}^{2}\right)$ & $1.82( \pm 0.20)$ & $24.4( \pm 2.7)$ & $24.4( \pm 2.8)$ \\
Body mass index $\left(\mathrm{kg} / \mathrm{m}^{2}\right)$ & $24.2( \pm 2.9)$ &
\end{tabular}

All continuous values are reported in mean \pm standard deviation (SD), while categories are reported as number (percentage)

$L V$ left ventricle, $R V$ right ventricle, EDV end-diastolic volume, ESV end-systolic volume, SV stroke volume, EF ejection fraction; indexed, absolute values divided by body surface area

inclusion criteria. The breakdown of the number of participants meeting individual exclusion criterion is available in Appendix 1. The mean age of the cohort was $59 \pm 7$ (range 45-74) years. Upon removing outliers, a total of 800 participants (368 males, 432 females) were included in the ventricular analysis and 795 participants (363 male, 432 female) in the atrial analysis (Fig. 2). Baseline characteristics for all participants are provided in Table 1. A summary of CMR parameters stratified by gender is presented in
Appendix 2, Tables 13 and 14. The association between CMR parameters and age stratified by gender is included in Appendix 2, Tables 14 and 15.

CMR left ventricular, right ventricular, left atrial and right atrial reference ranges are provided in a traffic light format for males and females for the whole cohort regardless of their age groups for both absolute and indexed values in numerical format (Tables 2, 3, 4 and 5). These tables are also presented together in a user-friendly poster format for clinical use which is available in Additional file 1. Age-

Table 2 Ventricular reference range for Caucausian men

\begin{tabular}{|c|c|c|c|c|c|}
\hline \multicolumn{6}{|l|}{ Left ventricle } \\
\hline LVEDV (ml) & $<93$ & \multirow{18}{*}{ 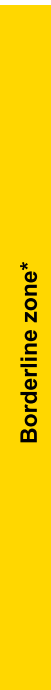 } & $109-218$ & \multirow{18}{*}{ 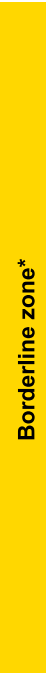 } & $>232$ \\
\hline LVESV (ml) & $<34$ & & $39-97$ & & $>103$ \\
\hline $\operatorname{LVSV}(\mathrm{ml})$ & $<49$ & & $59-132$ & & $>140$ \\
\hline LV mass (g) & $<56$ & & $64-141$ & & $>148$ \\
\hline indexed LVEDV $\left(\mathrm{ml} / \mathrm{m}^{2}\right)$ & $<52$ & & $60-110$ & & $>117$ \\
\hline indexed LVESV $\left(\mathrm{ml} / \mathrm{m}^{2}\right)$ & $<19$ & & $21-49$ & & $>52$ \\
\hline indexed LVSV $\left(\mathrm{ml} / \mathrm{m}^{2}\right)$ & $<28$ & & $32-67$ & & $>70$ \\
\hline indexed LV mass $\left(\mathrm{g} / \mathrm{m}^{2}\right)$ & $<33$ & & $35-70$ & & $>72$ \\
\hline LVEF $(\%)$ & $<47$ & & $48-69$ & & $>70$ \\
\hline LV mass to volume ratio $(\mathrm{g} / \mathrm{ml})$ & $<0.40$ & & $0.42-0.84$ & & $>0.87$ \\
\hline \multicolumn{4}{|l|}{ Right ventricle } & & \\
\hline RVEDV (ml) & $<99$ & & $124-248$ & & $>260$ \\
\hline RVESV (ml) & $<34$ & & $47-123$ & & $>135$ \\
\hline RVSV (ml) & $<54$ & & $62-131$ & & $>140$ \\
\hline indexed RVEDV $\left(\mathrm{ml} / \mathrm{m}^{2}\right)$ & $<55$ & & $68-125$ & & $>128$ \\
\hline indexed RVESV $\left(\mathrm{ml} / \mathrm{m}^{2}\right)$ & $<19$ & & $25-63$ & & $>67$ \\
\hline indexed RVSV $\left(\mathrm{ml} / \mathrm{m}^{2}\right)$ & $<30$ & & $34-67$ & & $>69$ \\
\hline RVEF (\%) & $<40$ & & $45-65$ & & $>68$ \\
\hline
\end{tabular}

Abnormal low and high refer to the lower and upper reference limits, respectively. They are defined as measurements which lie outside the $95 \%$ prediction interval at all age groups

${ }^{a}$ Borderline zone values should be looked up in the age-specific tables. The borderline zone was defined as the upper and lower ranges where the measured value lay outside the $95 \%$ prediction interval for at least one age group

$L V$ left ventricle, $R V$ right ventricle, EDV end-diastolic volume, ESV end-systolic volume, SV stroke volume, EF ejection fraction; indexed, absolute values divided by body surface area 
Table 3 Ventricular reference range for Caucausian women

\begin{tabular}{|c|c|c|c|c|c|}
\hline & Abnormal low & & Normal zone & & Abnormal high \\
\hline \multicolumn{6}{|l|}{ Left ventricle } \\
\hline LVEDV (ml) & $<80$ & \multirow{18}{*}{ 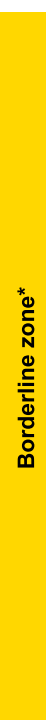 } & $88-161$ & \multirow{18}{*}{ 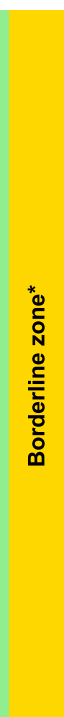 } & $>175$ \\
\hline LVESV (ml) & $<25$ & & $31-68$ & & $>73$ \\
\hline LVSV (ml) & $<47$ & & $49-100$ & & $>110$ \\
\hline LV mass $(\mathrm{g})$ & $<44$ & & $46-93$ & & $>96$ \\
\hline indexed LVEDV $\left(\mathrm{ml} / \mathrm{m}^{2}\right)$ & $<50$ & & $54-94$ & & $>101$ \\
\hline indexed LVESV $\left(\mathrm{ml} / \mathrm{m}^{2}\right)$ & $<16$ & & $19-40$ & & $>43$ \\
\hline indexed LVSV $\left(\mathrm{ml} / \mathrm{m}^{2}\right)$ & $<29$ & & $30-59$ & & $>63$ \\
\hline indexed LV mass $\left(\mathrm{g} / \mathrm{m}^{2}\right)$ & $<28$ & & $29-55$ & & $>55$ \\
\hline $\operatorname{LVEF}(\%)$ & $<50$ & & $51-70$ & & $>72$ \\
\hline LV mass to volume ratio $(\mathrm{g} / \mathrm{ml})$ & $<0.35$ & & $0.39-0.71$ & & $>0.81$ \\
\hline Right ventricle & & & & & \\
\hline RVEDV (ml) & $<83$ & & $85-168$ & & $>192$ \\
\hline RVESV (ml) & $<26$ & & $27-77$ & & $>95$ \\
\hline $\operatorname{RVSV}(\mathrm{ml})$ & $<47$ & & $48-99$ & & $>107$ \\
\hline indexed RVEDV $\left(\mathrm{ml} / \mathrm{m}^{2}\right)$ & $<51$ & & $53-99$ & & $>110$ \\
\hline indexed RVESV $\left(\mathrm{ml} / \mathrm{m}^{2}\right)$ & $<16$ & & $17-46$ & & $>55$ \\
\hline indexed RVSV $\left(\mathrm{ml} / \mathrm{m}^{2}\right)$ & $<29$ & & $30-59$ & & $>61$ \\
\hline RVEF (\%) & $<45$ & & $47-68$ & & $>70$ \\
\hline
\end{tabular}

Abnormal low and high refer to the lower and upper reference limits, respectively. They are defined as measurements which lie outside the $95 \%$ prediction interval at all age groups

${ }^{a}$ Borderline zone values should be looked up in the age-specific tables. The borderline zone was defined as the upper and lower ranges where the measured value lay outside the $95 \%$ prediction interval for at least one age group

$L V$ left ventricle, $R V$ right ventricle, EDV end-diastolic volume, ESV end-systolic volume, SV stroke volume, EF ejection fraction; indexed, absolute values divided by body surface area

Table 4 Atrial reference range for Caucausian men

\begin{tabular}{|c|c|c|c|c|c|}
\hline & Abnormal low & & Normal zone & & Abnormal high \\
\hline \multicolumn{6}{|l|}{ Left atrium } \\
\hline Max. LA volume $(2 \mathrm{Ch})(\mathrm{ml})$ & $<22$ & \multirow{14}{*}{ 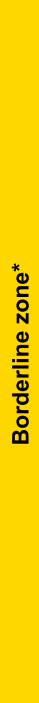 } & $30-104$ & \multirow{14}{*}{ 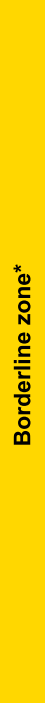 } & $>112$ \\
\hline Max. LA volume (4Ch) (ml) & $<23$ & & $36-124$ & & $>125$ \\
\hline Max. LA volume (Biplane) (ml) & $<26$ & & $37-108$ & & $>112$ \\
\hline LA SV (Biplane) (ml) & $<16$ & & $23-62$ & & $>66$ \\
\hline $\begin{array}{l}\text { indexed Max. LA volume }(2 \mathrm{Ch}) \\
\left(\mathrm{ml} / \mathrm{m}^{2}\right)\end{array}$ & $<12$ & & $16-53$ & & $>56$ \\
\hline $\begin{array}{l}\text { indexed Max. LA volume }(4 \mathrm{Ch}) \\
\left(\mathrm{ml} / \mathrm{m}^{2}\right)\end{array}$ & $<14$ & & $19-62$ & & $>63$ \\
\hline $\begin{array}{l}\text { indexed Max. LA volume (Biplane) } \\
\left(\mathrm{ml} / \mathrm{m}^{2}\right)\end{array}$ & $<15$ & & $19-55$ & & $>56$ \\
\hline indexed LA SV (Biplane) $\left(\mathrm{ml} / \mathrm{m}^{2}\right)$ & $<9$ & & $12-32$ & & $>33$ \\
\hline $\begin{array}{l}\text { LA EF (Biplane) }(\%) \\
\text { Right atrium }\end{array}$ & $<44$ & & $47-73$ & & $>75$ \\
\hline Max. RA volume (4Ch) (ml) & $<36$ & & $43-143$ & & $>150$ \\
\hline RA SV (4Ch) (ml) & $<9$ & & $10-66$ & & $>66$ \\
\hline $\begin{array}{l}\text { indexed Max. RA volume }(4 \mathrm{Ch}) \\
\left(\mathrm{ml} / \mathrm{m}^{2}\right)\end{array}$ & $<19$ & & $22-74$ & & $>79$ \\
\hline indexed RA SV $(4 \mathrm{Ch})\left(\mathrm{ml} / \mathrm{m}^{2}\right)$ & $<5$ & & $5-33$ & & $>35$ \\
\hline RA EF (4Ch) (\%) & $<21$ & & $23-58$ & & $>60$ \\
\hline
\end{tabular}

Abnormal low and high refer to the lower and upper reference limits, respectively. They are defined as measurements which lie outside the $95 \%$ prediction interval at all age groups

${ }^{a}$ Borderline zone values should be looked up in the age-specific tables. The borderline zone was defined as the upper and lower ranges where the measured value lay outside the $95 \%$ prediction interval for at least one age group

$L A$ left atrium, $R A$ right atrium, SV stroke volume, EF ejection fraction, $2 C h$ two-chamber, $4 C h$ four-chamber, Biplane derived from four-chamber and two-chamber views; indexed, absolute values divided by body surface area 
Table 5 Atrial reference range for Caucausian women

\begin{tabular}{|c|c|c|c|c|c|}
\hline & Abnormal low & & Normal zone & & Abnormal high \\
\hline \multicolumn{6}{|l|}{ Left atrium } \\
\hline Max. LA volume $(2 \mathrm{Ch})(\mathrm{ml})$ & $<19$ & \multirow{14}{*}{ 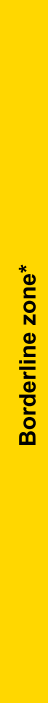 } & $24-90$ & \multirow{14}{*}{ 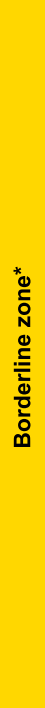 } & $>97$ \\
\hline Max. LA volume $(4 \mathrm{Ch})(\mathrm{ml})$ & $<23$ & & $36-108$ & & $>114$ \\
\hline Max. LA volume (Biplane) (ml) & $<26$ & & $33-93$ & & $>100$ \\
\hline LA SV (Biplane) (ml) & $<17$ & & $21-53$ & & $>60$ \\
\hline $\begin{array}{l}\text { indexed Max. LA volume }(2 \mathrm{Ch}) \\
\left(\mathrm{ml} / \mathrm{m}^{2}\right)\end{array}$ & $<12$ & & $15-53$ & & $>56$ \\
\hline $\begin{array}{l}\text { indexed Max. LA volume }(4 \mathrm{Ch}) \\
\left(\mathrm{ml} / \mathrm{m}^{2}\right)\end{array}$ & $<15$ & & $23-63$ & & $>67$ \\
\hline $\begin{array}{l}\text { indexed Max. LA volume (Biplane) } \\
\left(\mathrm{ml} / \mathrm{m}^{2}\right)\end{array}$ & $<16$ & & $21-55$ & & $>57$ \\
\hline indexed LA SV (Biplane) $\left(\mathrm{ml} / \mathrm{m}^{2}\right)$ & $<10$ & & $13-32$ & & $>34$ \\
\hline $\begin{array}{l}\text { LA EF (Biplane) }(\%) \\
\text { Right atrium }\end{array}$ & $<44$ & & $49-74$ & & $>77$ \\
\hline Max. RA volume (4Ch) (ml) & $<34$ & & $38-101$ & & $>107$ \\
\hline RA SV (4Ch) (ml) & $<10$ & & $14-52$ & & $>54$ \\
\hline $\begin{array}{l}\text { indexed Max. RA volume }(4 \mathrm{Ch}) \\
\left(\mathrm{ml} / \mathrm{m}^{2}\right)\end{array}$ & $<20$ & & $23-59$ & & $>63$ \\
\hline indexed RA SV $(4 \mathrm{Ch})\left(\mathrm{ml} / \mathrm{m}^{2}\right)$ & $<6$ & & $8-31$ & & $>32$ \\
\hline RA EF (4Ch) (\%) & $<26$ & & $31-63$ & & $>66$ \\
\hline
\end{tabular}

Abnormal low and high refer to the lower and upper reference limits, respectively. They are defined as measurements which lie outside the $95 \%$ prediction interval at all age groups

${ }^{a}$ Borderline zone values should be looked up in the age-specific tables. The borderline zone was defined as the upper and lower ranges where the measured value lay outside the $95 \%$ prediction interval for at least one age group

$L A$ left atrium, RA right atrium, SV stroke volume, EF ejection fraction, $2 \mathrm{Ch}$ two-chamber, $4 \mathrm{Ch}$ four-chamber, Biplane derived from four-chamber and two-chamber views; indexed, absolute values divided by body surface area

specific reference ranges are also provided in 'look-up' tables for those measured CMR values in the borderline (yellow) zone. (Tables 6, 7, 8, 9)

\section{Left ventricle}

LV end-diastolic volume and LV end-systolic volume were significantly larger in males (LV EDV: absolute $=166 \pm$ $32 \mathrm{ml}$, indexed $=85 \pm 15 \mathrm{ml}$; LV ESV: absolute $=69 \pm 16 \mathrm{ml}$, indexed $=36 \pm 8 \mathrm{ml}$ ) compared to females (LV EDV: absolute $=124 \pm 21 \mathrm{ml}$, indexed $=74 \pm 12 \mathrm{ml}$; LV ESV: absolute $=49 \pm 11 \mathrm{ml}$, indexed $=29 \pm 6 \mathrm{ml}$ ) for both absolute and indexed values. (Appendix 2, Table 12) In men, LV end-diastolic volumes and stroke volumes were lower with older age for both absolute and indexed values. (Appendix 2, Table 14) In women, LV end-diastolic volume, endsystolic volume and stroke volume were smaller with advancing age for absolute and indexed values. LV ejection fraction was significantly greater in females $(61 \pm 5 \%)$ compared to males $(58 \pm 5 \%)$. LV ejection fraction demonstrated no correlation with age in neither males nor females. LV mass was significantly higher in males (103 \pm $21 \mathrm{~g})$ compared to females $(70 \pm 13 \mathrm{~g})$. Upon normalization for body surface area, LV mass did not change significantly with age in either gender. In females, LV mass to end-diastolic volume ratio, a measure of distinct patterns of anatomical adaptations [17], increased significantly $(r=0.14, p<0.01)$ with age; this was not demonstrated in males.

\section{Right ventricle}

RV end-diastolic volume and RV end-systolic volume were significantly larger in males (RV EDV: absolute $=182 \pm 36 \mathrm{ml}$, indexed $=93 \pm 17 \mathrm{ml}$; RV ESV: absolute $=85 \pm 22 \mathrm{ml}$, indexed $=43 \pm 11 \mathrm{ml}$ ) compared to females (RV EDV: absolute $=130 \pm 24 \mathrm{ml}$, indexed $=$ $77 \pm 13 \mathrm{ml}$; RV ESV: absolute $=55 \pm 15 \mathrm{ml}$, indexed $=$ $33 \pm 9 \mathrm{ml}$ ) for both absolute and indexed values. Both RV end-diastolic volume and end-systolic volume were lower in older age groups in males and females for absolute and indexed values. RV ejection fraction was significantly higher in females $(58 \pm 6 \%)$ compared to males $(54 \pm 6 \%)$. RV ejection fraction demonstrated a weak but significant positive correlation with advancing age in females only $(r=0.1, p<0.05)$.

\section{Left and right atria}

Left and right atrial reference ranges are presented in Tables 4, 5, 8 and 9. LA maximal volume and stroke volume, as determined by the biplane method, were significantly larger in males compared to females for absolute values $(71 \pm$ 19 vs $62 \pm 17 \mathrm{ml})$ but not for BSA-indexed values ( $36 \pm 9$ vs $37 \pm 10 \mathrm{ml})$. LA ejection fraction was almost identical ( $60 \% \mathrm{vs}$ 
Table 6 Age-specific ventricular reference ranges for Caucausian men

\begin{tabular}{|c|c|c|c|c|c|c|c|c|c|}
\hline & \multicolumn{9}{|c|}{ Age groups (years) } \\
\hline & & $45-54$ & & & $55-64$ & & & $65-74$ & \\
\hline & lower & mean & upper & lower & mean & upper & lower & mean & upper \\
\hline LVEDV (ml) & 109 & 170 & 232 & 108 & 169 & 230 & 93 & 156 & 218 \\
\hline LVESV (ml) & 39 & 71 & 103 & 39 & 71 & 102 & 34 & 66 & 97 \\
\hline LVSV (ml) & 58 & 99 & 140 & 59 & 98 & 137 & 49 & 90 & 132 \\
\hline LV mass (g) & 64 & 106 & 148 & 64 & 104 & 143 & 56 & 99 & 141 \\
\hline $\begin{array}{l}\text { indexed LVEDV } \\
\left(\mathrm{ml} / \mathrm{m}^{2}\right)\end{array}$ & 60 & 86 & 112 & 55 & 86 & 117 & 52 & 81 & 110 \\
\hline $\begin{array}{l}\text { indexed LVESV } \\
\left(\mathrm{ml} / \mathrm{m}^{2}\right)\end{array}$ & 21 & 36 & 51 & 20 & 36 & 52 & 19 & 34 & 49 \\
\hline $\begin{array}{l}\text { indexed LVSV } \\
\left(\mathrm{ml} / \mathrm{m}^{2}\right)\end{array}$ & 32 & 50 & 68 & 30 & 50 & 70 & 28 & 47 & 67 \\
\hline $\begin{array}{l}\text { indexed LV mass } \\
\left(\mathrm{g} / \mathrm{m}^{2}\right)\end{array}$ & 35 & 54 & 72 & 34 & 53 & 72 & 33 & 51 & 70 \\
\hline LVEF (\%) & 47 & 58 & 70 & 48 & 58 & 69 & 47 & 58 & 69 \\
\hline $\begin{array}{l}\mathrm{LV} \text { mass to } \\
\text { volume ratio } \\
(\mathrm{g} / \mathrm{ml})\end{array}$ & 0.42 & 0.63 & 0.84 & 0.40 & 0.62 & 0.85 & 0.41 & 0.64 & 0.87 \\
\hline RVEDV (ml) & 124 & 192 & 260 & 109 & 181 & 252 & 99 & 173 & 248 \\
\hline RVESV (ml) & 47 & 91 & 135 & 42 & 82 & 123 & 34 & 81 & 129 \\
\hline RVSV (ml) & 62 & 101 & 140 & 60 & 98 & 136 & 54 & 92 & 131 \\
\hline $\begin{array}{l}\text { indexed RVEDV } \\
\left(\mathrm{ml} / \mathrm{m}^{2}\right)\end{array}$ & 68 & 97 & 126 & 56 & 92 & 128 & 55 & 90 & 125 \\
\hline $\begin{array}{l}\text { indexed RVESV } \\
\left(\mathrm{ml} / \mathrm{m}^{2}\right)\end{array}$ & 25 & 46 & 67 & 21 & 42 & 63 & 19 & 42 & 66 \\
\hline $\begin{array}{l}\text { indexed RVSV } \\
\left(\mathrm{ml} / \mathrm{m}^{2}\right)\end{array}$ & 34 & 51 & 68 & 31 & 50 & 69 & 30 & 48 & 67 \\
\hline RVEF (\%) & 40 & 53 & 65 & 45 & 55 & 65 & 40 & 54 & 68 \\
\hline
\end{tabular}

Male left and right atrial reference ranges detailing mean, lower reference limit and upper reference limit by age group. Reference limits are derived by the upper and lower bounds of the $95 \%$ prediction interval for each parameter at each age group

$L V$ left ventricle, $R V$ right ventricle, EDV end-diastolic volume, ESV end-systolic volume, SV stroke volume, EF ejection fraction; indexed, absolute values divided by body surface area

61\%) in males and females. Upon normalization for BSA, there was no change in left atrial volumes or function with age in men. In women, indexed LA stroke volume was significantly lower $(\mathrm{r}=-0.2, p<0.001)$ with advancing age.

RA maximal volume and stroke volume were significantly larger in males (RA absolute maximal volume $=93 \pm 27 \mathrm{ml}$, $\mathrm{RA}$ absolute stroke volume $=38 \pm 14 \mathrm{ml}$ ) compared to females (RA absolute maximal volume $=69 \pm 17 \mathrm{ml}$, RA absolute stroke volume $=32 \pm 10 \mathrm{ml}$ ) for absolute values; upon indexing for BSA, this effect was seen for RA maximal volume only ( $48 \pm 14$ vs $41 \pm 10 \mathrm{ml})$. RA ejection fraction was significantly higher ( $46 \%$ vs $41 \%, p<0.001)$ in females compared to males. Upon normalization for BSA, there was no change in right atrial volumes or function with age in males or females.

\section{Intra- and inter-observer variability}

Intra and inter-observer variability data is presented in Table 10 and as Bland-Altman plots (representative examples of all observers) in Appendix 3, Figures 3, 4 and 5.
Good to excellent intra- and inter-observer variability was achieved for LV and RV end-diastolic volume, end-systolic volume and stroke volume and LA and RA maximal volume and stroke volume.

\section{Discussion}

The present study provides clinically relevant age- and gender-specific CMR reference ranges in a traffic light system for the left ventricular, right ventricular, left atrial and right atrial chambers derived from a cohort of 804 Caucasian adults aged 45-74 strictly free from pathophysiological or environmental risk factors affecting cardiac structure or function at 1.5 Tesla.

Whilst determination of reference ranges for CMR has been performed by several previous studies, this work is novel for a number or reasons. Firstly, the substantially larger cohort with strict evidence to ensure participants are free of biological or environmental factors known to impact upon cardiac structure or function differentiates this study from its predecessors. Secondly, reference ranges for CMR parameters 
Table 7 Age-specific ventricular reference ranges for Caucausian women

\begin{tabular}{|c|c|c|c|c|c|c|c|c|c|}
\hline & \multicolumn{9}{|c|}{ Age groups (years) } \\
\hline & & $45-54$ & & & $55-64$ & & & $65-74$ & \\
\hline & lower & mean & upper & lower & mean & upper & lower & mean & upper \\
\hline LVEDV (ml) & 88 & 131 & 175 & 80 & 121 & 161 & 81 & 122 & 163 \\
\hline LVESV (ml) & 31 & 52 & 73 & 26 & 47 & 68 & 25 & 48 & 70 \\
\hline LVSV (ml) & 49 & 79 & 110 & 47 & 74 & 100 & 47 & 74 & 100 \\
\hline LV mass (g) & 46 & 71 & 96 & 45 & 69 & 93 & 44 & 69 & 94 \\
\hline $\begin{array}{l}\text { indexed LVEDV } \\
\left(\mathrm{ml} / \mathrm{m}^{2}\right)\end{array}$ & 54 & 78 & 101 & 50 & 72 & 94 & 50 & 73 & 96 \\
\hline $\begin{array}{l}\text { indexed LVESV } \\
\left(\mathrm{ml} / \mathrm{m}^{2}\right)\end{array}$ & 19 & 31 & 43 & 16 & 28 & 40 & 16 & 29 & 42 \\
\hline $\begin{array}{l}\text { indexed LVSV } \\
\left(\mathrm{ml} / \mathrm{m}^{2}\right)\end{array}$ & 30 & 47 & 63 & 29 & 44 & 59 & 29 & 45 & 60 \\
\hline $\begin{array}{l}\text { indexed LV mass } \\
\left(\mathrm{g} / \mathrm{m}^{2}\right)\end{array}$ & 29 & 42 & 55 & 28 & 41 & 55 & 28 & 42 & 55 \\
\hline LVEF (\%) & 50 & 60 & 70 & 51 & 61 & 72 & 50 & 61 & 72 \\
\hline $\begin{array}{l}\text { LV mass to } \\
\text { volume ratio } \\
(\mathrm{g} / \mathrm{ml})\end{array}$ & 0.39 & 0.55 & 0.71 & 0.36 & 0.58 & 0.8 & 0.35 & 0.58 & 0.81 \\
\hline RVEDV (ml) & 85 & 138 & 192 & 83 & 125 & 168 & 84 & 128 & 171 \\
\hline RVESV (ml) & 27 & 61 & 95 & 27 & 52 & 77 & 26 & 54 & 82 \\
\hline RVSV (ml) & 48 & 78 & 107 & 47 & 73 & 100 & 48 & 74 & 99 \\
\hline $\begin{array}{l}\text { indexed RVEDV } \\
\left(\mathrm{ml} / \mathrm{m}^{2}\right)\end{array}$ & 53 & 81 & 110 & 51 & 75 & 99 & 53 & 77 & 101 \\
\hline $\begin{array}{l}\text { indexed RVESV } \\
\left(\mathrm{ml} / \mathrm{m}^{2}\right)\end{array}$ & 17 & 36 & 55 & 16 & 31 & 46 & 17 & 32 & 48 \\
\hline $\begin{array}{l}\text { indexed RVSV } \\
\left(\mathrm{ml} / \mathrm{m}^{2}\right)\end{array}$ & 30 & 46 & 61 & 29 & 44 & 59 & 30 & 44 & 59 \\
\hline RVEF (\%) & 45 & 56 & 68 & 47 & 59 & 70 & 46 & 58 & 70 \\
\hline
\end{tabular}

Male left and right atrial reference ranges detailing mean, lower reference limit and upper reference limit by age group. Reference limits are derived by the upper and lower bounds of the $95 \%$ prediction interval for each parameter at each age group

$L V$ left ventricle, $R V$ right ventricle, EDV end-diastolic volume, ESV end-systolic volume, SV stroke volume, EF ejection fraction; indexed, absolute values divided by body surface area

are detailed not only by gender but also by age decade, thereby providing increased granularity and clinical utility. Thirdly, previously described findings are reinforced, particularly with respect to age- and gender-related differences in ventricular and atrial parameters. Fourthly, in-depth data surrounding intra- and inter-observer variability is provided.

The validity of a reference range is dependent on a number of factors, including the number of observations available in order to determine the reference interval [12]. This study utilises 800 participants for derivation of left and right ventricular reference ranges. This is a substantial increase compared to the majority of previous studies describing ventricular reference ranges using the SSFP technique: Alfakih et al. [3] $(n=60)$, Hudsmith et al. [2] $(n=108)$, Maceira et al. [1] $(n=120)$ and similar to those published by the Framingham Heart Study group. Similarly, 795 participants are included for derivation of left and right atrial reference ranges. Although previous studies outlining atrial reference ranges have used differing techniques, again, all utilise substantially fewer participants: Sievers et al. [18] $(n=111)$, Hudsmith et al. [2] $(n=108)$, Maceira et al. [19, 20] $(n=120)$. Even a recent systematic review and meta-analysis of normal values for CMR in adults and children is based on smaller numbers than the normal reference ranges presented here [4]. A recently published paper by Gandy and colleagues presents LV reference ranges for 1,515 UK individuals scanned at 3 Tesla [21]. However, their study population includes participants with high plasma $\mathrm{B}$ type natriuretic peptide (BNP) levels and blood pressure $>149 / 95 \mathrm{mmHg}$ by design, thus, could not be considered strictly healthy. Le Van et al. describes ventricular and atrial reference values derived from 434 Caucasian adults with similar exclusion criteria to the present study [22]. However, their study examines a much younger cohort, aged 18 to 35 years, and thus the present study complements their findings by investigating an older age range.

Furthermore, this study complied with approved statistical recommendations on derivation of reference limits [12]. Data 
Table 8 Age-specific atrial reference ranges for Caucausian men

\begin{tabular}{|c|c|c|c|c|c|c|c|c|c|}
\hline & \multicolumn{9}{|c|}{ Age groups (years) } \\
\hline & \multicolumn{3}{|c|}{$45-54$} & \multicolumn{3}{|c|}{$55-64$} & \multicolumn{3}{|c|}{$65-74$} \\
\hline & lower & mean & upper & lower & mean & upper & lower & mean & upper \\
\hline $\begin{array}{l}\text { Maximal LA volume } \\
(2 \mathrm{Ch})(\mathrm{ml})\end{array}$ & 25 & 68 & 112 & 30 & 68 & 105 & 22 & 63 & 104 \\
\hline $\begin{array}{l}\text { Maximal LA volume } \\
(4 \mathrm{Ch})(\mathrm{ml})\end{array}$ & 33 & 79 & 124 & 36 & 80 & 125 & 23 & 74 & 124 \\
\hline $\begin{array}{l}\text { Maximal LA volume } \\
\text { (Biplane) }(\mathrm{ml})\end{array}$ & 33 & 72 & 112 & 37 & 73 & 110 & 26 & 67 & 108 \\
\hline LA SV (Biplane) (ml) & 20 & 43 & 66 & 23 & 44 & 65 & 16 & 39 & 62 \\
\hline $\begin{array}{l}\text { indexed Maximal LA } \\
\text { volume }(2 \mathrm{Ch}) \\
\left(\mathrm{ml} / \mathrm{m}^{2}\right)\end{array}$ & 13 & 35 & 56 & 16 & 34 & 53 & 12 & 33 & 53 \\
\hline $\begin{array}{l}\text { indexed Maximal LA } \\
\text { volume }(4 \mathrm{Ch}) \\
\left(\mathrm{ml} / \mathrm{m}^{2}\right)\end{array}$ & 18 & 40 & 62 & 19 & 41 & 63 & 14 & 38 & 63 \\
\hline $\begin{array}{l}\text { indexed Maximal LA } \\
\text { volume (Biplane) } \\
\left(\mathrm{ml} / \mathrm{m}^{2}\right)\end{array}$ & 18 & 37 & 56 & 19 & 37 & 55 & 15 & 35 & 55 \\
\hline $\begin{array}{l}\text { indexed LA SV } \\
\text { (Biplane) }\left(\mathrm{ml} / \mathrm{m}^{2}\right)\end{array}$ & 11 & 22 & 33 & 12 & 22 & 33 & 9 & 21 & 32 \\
\hline LA EF (Biplane) (\%) & 45 & 59 & 73 & 47 & 61 & 75 & 44 & 59 & 74 \\
\hline $\begin{array}{l}\text { Maximal RA volume } \\
(4 \mathrm{Ch})(\mathrm{ml})\end{array}$ & 38 & 93 & 148 & 43 & 93 & 143 & 36 & 93 & 150 \\
\hline RA SV (4Ch) (ml) & 10 & 38 & 66 & 10 & 38 & 66 & 9 & 38 & 66 \\
\hline $\begin{array}{l}\text { indexed Maximal RA } \\
\text { volume }(4 \mathrm{Ch}) \\
\left(\mathrm{ml} / \mathrm{m}^{2}\right)\end{array}$ & 20 & 47 & 75 & 22 & 48 & 74 & 19 & 49 & 79 \\
\hline $\begin{array}{l}\text { indexed RA SV } \\
(4 \mathrm{Ch})\left(\mathrm{ml} / \mathrm{m}^{2}\right)\end{array}$ & 5 & 19 & 33 & 5 & 20 & 34 & 5 & 20 & 35 \\
\hline RA EF (4Ch) (\%) & 23 & 40 & 58 & 21 & 41 & 60 & 22 & 41 & 60 \\
\hline
\end{tabular}

Male left and right atrial reference ranges detailing mean, lower reference limit and upper reference limit by age group. Reference limits are derived by the upper and lower bounds of the $95 \%$ prediction interval for each parameter at each age group

LA left atrium, RA right atrium, SV stroke volume, EF ejection fraction, $2 \mathrm{Ch}$ two-chamber, 4Ch four-chamber, Biplane derived from four-chamber and two-chamber views; indexed, absolute values divided by body surface area

has been partitioned - dividing reference values by age and sex - in order to reduce variation. The distribution of the reference values was inspected and assessed for normality and values identified as outliers discarded as per our a priori definition.

A total of 5,065 CMR examinations of UK Biobank participants were analysed for this study. Utilising this large population sample permitted a posteriori (retrospective) selection of the reference sample, the preferred method when compiling reference values from healthy individuals [23]. Indeed, only $16 \%$ of the original sample were included in this study, with rule-out criteria extending beyond known cardiovascular disease to include traditional cardiovascular risk factors (diabetes mellitus, hypercholesterolaemia, hypertension, current- and extobacco smokers, obesity), cardiovascular symptoms, current or previous cancer, stroke, respiratory, renal or haematological disease and use of certain pharmacological agents. In doing so, a robust definition of what constitutes "health" was created, permitting confidence that reference ranges for cardiovascular structure and function in CMR have been derived from an appropriately selected cohort. This contrasts to the LV reference values published from the Framingham Heart Study Offspring Cohort where the healthy reference group consisted of $47.5 \%$ of the total cohort, and exclusion criteria were a history of hypertension, history of use of antihypertensive medication, previous myocardial infarction and heart failure only. Similarly, in the RV reference values study published by the same group, the "healthy reference" cohort included participants with hypertension, diabetes, hypercholesterolaemia and those who were current tobacco smokers [6].

For the left ventricle, our findings that men demonstrated greater volumes and mass compared to females is consistent with both the CMR literature [4] and that derived from other imaging modalities [24, 25]. Our demonstration of decreasing LV end-diastolic and endsystolic volumes with advancing age is also consistent with previous findings. Values for LV end-diastolic volumes are similar to those described by Hudsmith [2], 
Table 9 Age-specific atrial reference ranges for Caucausian women

\begin{tabular}{|c|c|c|c|c|c|c|c|c|c|}
\hline & \multicolumn{9}{|c|}{ Age groups (years) } \\
\hline & \multicolumn{3}{|c|}{$45-54$} & \multicolumn{3}{|c|}{$55-64$} & \multicolumn{3}{|c|}{$65-74$} \\
\hline & lower & mean & upper & lower & mean & upper & lower & mean & upper \\
\hline $\begin{array}{l}\text { Maximal LA volume } \\
(2 \mathrm{Ch})(\mathrm{ml})\end{array}$ & 24 & 60 & 97 & 19 & 56 & 92 & 21 & 56 & 90 \\
\hline $\begin{array}{l}\text { Maximal LA volume } \\
(4 \mathrm{Ch})(\mathrm{ml})\end{array}$ & 36 & 75 & 114 & 27 & 68 & 108 & 23 & 68 & 113 \\
\hline $\begin{array}{l}\text { Maximal LA volume } \\
\text { (Biplane) }(\mathrm{ml})\end{array}$ & 33 & 66 & 100 & 26 & 60 & 95 & 28 & 61 & 93 \\
\hline LA SV (Biplane) (ml) & 21 & 41 & 60 & 17 & 36 & 55 & 18 & 35 & 53 \\
\hline $\begin{array}{l}\text { indexed Maximal LA } \\
\text { volume }(2 \mathrm{Ch}) \\
\left(\mathrm{ml} / \mathrm{m}^{2}\right)\end{array}$ & 15 & 35 & 56 & 12 & 33 & 54 & 14 & 34 & 53 \\
\hline $\begin{array}{l}\text { indexed Maximal LA } \\
\text { volume }(4 \mathrm{Ch}) \\
\left(\mathrm{ml} / \mathrm{m}^{2}\right)\end{array}$ & 23 & 44 & 65 & 17 & 40 & 63 & 15 & 41 & 67 \\
\hline $\begin{array}{l}\text { indexed Maximal LA } \\
\text { volume (Biplane) } \\
\left(\mathrm{ml} / \mathrm{m}^{2}\right)\end{array}$ & 21 & 39 & 57 & 16 & 36 & 56 & 18 & 36 & 55 \\
\hline $\begin{array}{l}\text { indexed LA SV } \\
\text { (Biplane) }\left(\mathrm{ml} / \mathrm{m}^{2}\right)\end{array}$ & 13 & 24 & 34 & 10 & 22 & 33 & 11 & 21 & 32 \\
\hline LA EF (Biplane) (\%) & 49 & 62 & 75 & 44 & 61 & 77 & 45 & 59 & 74 \\
\hline $\begin{array}{l}\text { Maximal RA volume } \\
(4 \mathrm{Ch})(\mathrm{ml})\end{array}$ & 38 & 70 & 101 & 34 & 67 & 101 & 36 & 71 & 107 \\
\hline RA SV (4Ch) (ml) & 14 & 33 & 53 & 10 & 31 & 52 & 11 & 33 & 54 \\
\hline $\begin{array}{l}\text { indexed Maximal RA } \\
\text { volume }(4 \mathrm{Ch}) \\
\left(\mathrm{ml} / \mathrm{m}^{2}\right)\end{array}$ & 23 & 41 & 59 & 20 & 40 & 60 & 23 & 43 & 63 \\
\hline $\begin{array}{l}\text { indexed RA SV } \\
(4 \mathrm{Ch})\left(\mathrm{ml} / \mathrm{m}^{2}\right)\end{array}$ & 8 & 20 & 31 & 6 & 19 & 31 & 7 & 20 & 32 \\
\hline RA EF (4Ch) (\%) & 31 & 48 & 65 & 26 & 46 & 66 & 28 & 45 & 63 \\
\hline
\end{tabular}

Male left and right atrial reference ranges detailing mean, lower reference limit and upper reference limit by age group. Reference limits are derived by the upper and lower bounds of the $95 \%$ prediction interval for each parameter at each age group

$L A$ left atrium, RA right atrium, SV stroke volume, EF ejection fraction, $2 \mathrm{Ch}$ two-chamber, $4 \mathrm{Ch}$ four-chamber, Biplane derived from four-chamber and two-chamber views; indexed, absolute values divided by body surface area

Kawel-Boehm [4] and the Framingham Offspring Cohort group. LV end-systolic volumes were larger, reflecting this study's methodology of including papillary muscles as part of the LV cavity - the technique most commonly employed when analysing clinical CMR examinations. Consequently, LV ejection fraction mean values and reference intervals were lower than previously reported. Despite this, the finding of a marginally, but significantly, lower LV ejection fraction in men compared to women is consistent with other large cohorts, including the Framingham Offspring Cohort, the Dallas Heart Study cohort [26] and the Multi-Ethnic Study of Atherosclerosis (MESA) cohort [27], although the latter two studies utilised the older gradient-recalled echo sequences. Our study demonstrated no change in LV ejection fraction across age groups, this is consistent with studies across imaging modalities [28, 29]. LV mass, upon normalization for BSA, did not change significantly across age groups in either gender. This is consistent with findings from the MESA cohort, but differs from the Framingham Offspring cohort which demonstrated a significant decrease in BSAnormalised LV mass with age. Autopsy-derived data concerning LV mass in individuals free from hypertension and coronary artery disease and corrected for BSA corroborate findings from our study, suggesting no change in cardiac mass with ageing [30].

For the right ventricle, our findings that males exhibited greater absolute and indexed volumes than females and that volumes were lower with advancing age in both genders are consistent with previously published literature. We demonstrated a larger RV ejection fraction in women compared to men, this is corroborated by Alfakih [3] using both SSFP and gradient-recalled echo sequences and by Foppa and Arora in the Framingham Offspring cohort [6].

For the atrial chambers, no consensus exists regarding the measurement of atrial volumes [4]. In this study, the LA was contoured in the 4-chamber and 2-chamber views and volumes calculated according to the biplane area-length method. Only Hudsmith presented LA 
Table 10 Inter- and intra-observer variability

\begin{tabular}{|c|c|c|}
\hline & $\begin{array}{l}\text { Inter-observer } \\
\mathrm{ICC}^{*}\end{array}$ & $\begin{array}{l}\text { Intra-observer } \\
\text { ICC range }^{\mathrm{a}}\end{array}$ \\
\hline \multicolumn{3}{|l|}{ Ventricle } \\
\hline LVEDV & 0.97 & $0.98-1.00$ \\
\hline LVESV & 0.88 & $0.95-0.97$ \\
\hline LVSV & 0.92 & $0.91-0.98$ \\
\hline LVEF & 0.71 & $0.80-0.92$ \\
\hline LV mass & 0.92 & $0.97-0.97$ \\
\hline LV mass to volume ratio & 0.92 & $0.79-0.97$ \\
\hline RVEDV & 0.92 & $0.98-0.99$ \\
\hline RVESV & 0.77 & $0.90-0.97$ \\
\hline RVSV & 0.89 & $0.93-0.98$ \\
\hline RVEF & 0.64 & $0.78-0.95$ \\
\hline \multicolumn{3}{|l|}{ Atrium } \\
\hline Maximal LA volume & 0.96 & $0.97-0.98$ \\
\hline LASV & 0.90 & $0.90-0.96$ \\
\hline LAEF & 0.64 & $0.75-0.93$ \\
\hline Maximal RA volume & 0.96 & $0.97-0.99$ \\
\hline RASV & 0.86 & $0.92-0.94$ \\
\hline RAEF & 0.75 & $0.84-0.88$ \\
\hline
\end{tabular}

ICC Intra-class correlation coefficient, $L V$ left ventricle, $R V$ right ventricle, $E D V$ end-diastolic volume, ESV end-systolic volume, SV stroke volume, EF ejection fraction, $L A$ left atrium, $R A$ right atrium

${ }^{*} p$-value $<0.001$

anange of all observers, $p$-value $<0.001$

reference ranges utilising a similar method with values for LA ejection fraction being almost identical to those described in this study. For the RA, the most recent work regarding reference ranges has been produced by Maceira et al. [20] using three-dimensional modelling which has not been undertaken in this study. Despite different methodology, general findings regarding absolute values being greater in males compared to females and no significant effect of age on RA volumes were replicated in our larger study.

\section{Clinical utility}

CMR measurements only provide meaningful information when compared to relevant reference values. However, comparison may be misleading if the CMR examination being considered does not adequately match the reference sample, particularly with regards to age and gender. It is known that cardiovascular disease predominantly affects individuals in middleand old-age, and it is individuals in these age groups who most commonly undergo CMR examinations. Furthermore, atrial and ventricular structure and function do not remain static over time and undergo changes with age, even in those without evidence of cardiovascular disease. It is in this context that this study presents absolute and BSA-indexed CMR reference values for men and women at three different age groups: $45-54,55-64$ and $65-74$.

\section{Intra- and inter-observer variability}

For LV and RV end-diastolic volume, end-systolic volume and stroke volume and LA and RA maximal volume and stroke volume, excellent inter- and intra-observer variability was achieved. It is notable, but perhaps not unsurprising, that ICC for derived parameters (i.e. ejection fraction) fell in comparison to those values for directly measured parameters. This is consistent with previous studies examining variability in CMR analysis, such as Margossian et al. [31] and Teo et al. [32], which reported very high interobserver ICC's for measured parameters which fell markedly when assessing the ejection fraction.

\section{Study limitations}

The reference intervals described were derived from a population of 45-74 year olds of Caucasian ethnicity and therefore may not be generalisable to other ethnic and age groups. As the UK Biobank Imaging project accumulates CMR imaging in up to 100,000 individuals in coming years, analysis of ethnicity effects will become feasible in due course. We included overweight participants with a BMI between 25 and $30 \mathrm{~kg} / \mathrm{m}^{2}$ in our reference range analysis, even though previous CMR publications, including our own, have shown that obesity affects cardiac structure and function even in an otherwise healthy population [33, 34]. Our rationale for this inclusion was two-fold: firstly, we aligned our inclusion criteria related to BMI with the "Recommendations for Cardiac Chamber Quantification by Echocardiography in Adults: An Update from the American Society of Echocardiography and the European Association of Cardiovascular Imaging" [10]; secondly, given that 2013 data from the UK demonstrates that only $32.9 \%$ of men and $42.8 \%$ of women had a BMI less than $25 \mathrm{~kg} / \mathrm{m}^{2}$, arguably our reference ranges represent the "new" normal range and are thus more applicable to the general population [35].

CMR examinations were not performed repeatedly on the same individuals over time, therefore the associations described between age and CMR parameters are not longitudinal, but rather crosssectional.

\section{Conclusions}

This study provides normal reference ranges for all four cardiac chambers derived from the largest healthy cohort of Caucasian adults and will provide utility in the analysis of CMR examinations in both clinical and research settings. 


\section{Appendix 1}

Table 11 Exclusion criteria

\begin{tabular}{lc}
\hline & Number (\%) \\
\hline Age & \\
$>74$ years & $119(2 \%)$
\end{tabular}

Medical conditions

\begin{tabular}{|c|c|}
\hline Hypertension & $1382(28 \%$ \\
\hline High cholesterol & $787(16 \%)$ \\
\hline Asthma & $628(13 \%)$ \\
\hline Hypothyroidism/myxoedema & $322(6 \%)$ \\
\hline Diabetes & $204(4 \%)$ \\
\hline Essential hypertension & $130(3 \%)$ \\
\hline Angina & $127(3 \%)$ \\
\hline Heart attack/myocardial infarction & $104(2 \%)$ \\
\hline Deep venous thrombosis (DVT) & $87(2 \%)$ \\
\hline Type 2 diabetes & $83(2 \%)$ \\
\hline Atrial fibrillation & $65(1 \%)$ \\
\hline Rheumatoid arthritis & $58(1 \%)$ \\
\hline Stroke & $58(1 \%)$ \\
\hline Emphysema/chronic bronchitis & $56(1 \%)$ \\
\hline Hyperthyroidism/thyrotoxicosis & $44(1 \%)$ \\
\hline Heart valve problem/heart murmur & $42(1 \%)$ \\
\hline Transient ischaemic attack (TIA) & $39(1 \%)$ \\
\hline Chronic obstructive airways disease/COPD & $39(1 \%)$ \\
\hline Pulmonary embolism +/- DVT & $38(1 \%)$ \\
\hline Iron deficiency anaemia & $33(1 \%)$ \\
\hline Ulcerative colitis & $31(1 \%)$ \\
\hline Heart arrhythmia & $31(1 \%)$ \\
\hline Heart/cardiac problem & $31(1 \%)$ \\
\hline Sleep apnoea & $28(1 \%)$ \\
\hline Polymyalgia rheumatica & $28(1 \%)$ \\
\hline Miscarriage & $22(0 \%)$ \\
\hline Irregular heart beat & $21(0 \%)$ \\
\hline Gestational hypertension/pre-eclampsia & $20(0 \%)$ \\
\hline Doctor diagnosed bronchiectasis_Yes & $18(0 \%)$ \\
\hline Anaemia & $18(0 \%)$ \\
\hline Ankylosing spondylitis & $18(0 \%)$ \\
\hline Rheumatic fever & $16(0 \%)$ \\
\hline Sarcoidosis & $15(0 \%)$ \\
\hline Peripheral vascular disease & $14(0 \%)$ \\
\hline Bronchiectasis & $14(0 \%)$ \\
\hline Diabetic eye disease & $14(0 \%)$ \\
\hline Crohns disease & $13(0 \%)$ \\
\hline Pernicious anaemia & $11(0 \%)$ \\
\hline Gestational diabetes only_Yes & $9(0 \%)$ \\
\hline Clotting disorder/excessive bleeding & $9(0 \%)$ \\
\hline
\end{tabular}

Table 11 Exclusion criteria (Continued)

\begin{tabular}{|c|c|}
\hline SVT / supraventricular tachycardia & $9(0 \%)$ \\
\hline Other respiratory problems & $8(0 \%)$ \\
\hline Sjogren's syndrome/sicca syndrome & $8(0 \%)$ \\
\hline Systemic lupus erythematosis/SLE & $8(0 \%)$ \\
\hline Renal/kidney failure & $8(0 \%)$ \\
\hline Low platelets/platelet disorder & $7(0 \%)$ \\
\hline Type 1 diabetes & $7(0 \%)$ \\
\hline Grave's disease & $6(0 \%)$ \\
\hline Heart failure/pulmonary edema & $6(0 \%)$ \\
\hline Gestational diabetes & $5(0 \%)$ \\
\hline Hereditary/genetic haematological disorder & $5(0 \%)$ \\
\hline Cardiomyopathy & $5(0 \%)$ \\
\hline Hyperparathyroidism & $5(0 \%)$ \\
\hline Nephritis & $5(0 \%)$ \\
\hline Haemochromatosis & $5(0 \%)$ \\
\hline Connective tissue disorder & $4(0 \%)$ \\
\hline Renal failure not requiring dialysis & $4(0 \%)$ \\
\hline Polycythaemia vera & $4(0 \%)$ \\
\hline Neutropenia/lymphopenia & $4(0 \%)$ \\
\hline Anorexia/bulimia/other eating disorder & $4(0 \%)$ \\
\hline Surgery/amputation of toe or leg_Do not know & $4(0 \%)$ \\
\hline Lymphoedema & $4(0 \%)$ \\
\hline Aortic stenosis & $4(0 \%)$ \\
\hline Retinal artery/vein occlusion & $4(0 \%)$ \\
\hline Inflammatory bowel disease & $3(0 \%)$ \\
\hline Adrenocortical insufficiency/Addison's disease & $3(0 \%)$ \\
\hline Hyperprolactinaemia & $3(0 \%)$ \\
\hline Surgery/amputation of toe or leg_Yes, toes & $3(0 \%)$ \\
\hline Atrial flutter & $3(0 \%)$ \\
\hline Mitral regurgitation/incompetence & $3(0 \%)$ \\
\hline Pericarditis & $3(0 \%)$ \\
\hline Hypertrophic cardiomyopathy (HCM / HOCM) & $3(0 \%)$ \\
\hline Emphysema & $3(0 \%)$ \\
\hline Kidney nephropathy & $3(0 \%)$ \\
\hline Myocarditis & $2(0 \%)$ \\
\hline Liver failure/cirrhosis & $2(0 \%)$ \\
\hline Diabetic neuropathy/ulcers & $2(0 \%)$ \\
\hline Leg claudication/intermittent claudication & $2(0 \%)$ \\
\hline Mitral valve disease & $2(0 \%)$ \\
\hline Mitral valve prolapse & $2(0 \%)$ \\
\hline Monoclonal gammopathy/not myeloma & $2(0 \%)$ \\
\hline Glomerulnephritis & $1(0 \%)$ \\
\hline Haemophilia & $1(0 \%)$ \\
\hline Vasculitis & $1(0 \%)$ \\
\hline Wegners granulmatosis & $1(0 \%)$ \\
\hline Sickle cell disease & $1(0 \%)$ \\
\hline
\end{tabular}


Table 11 Exclusion criteria (Continued)

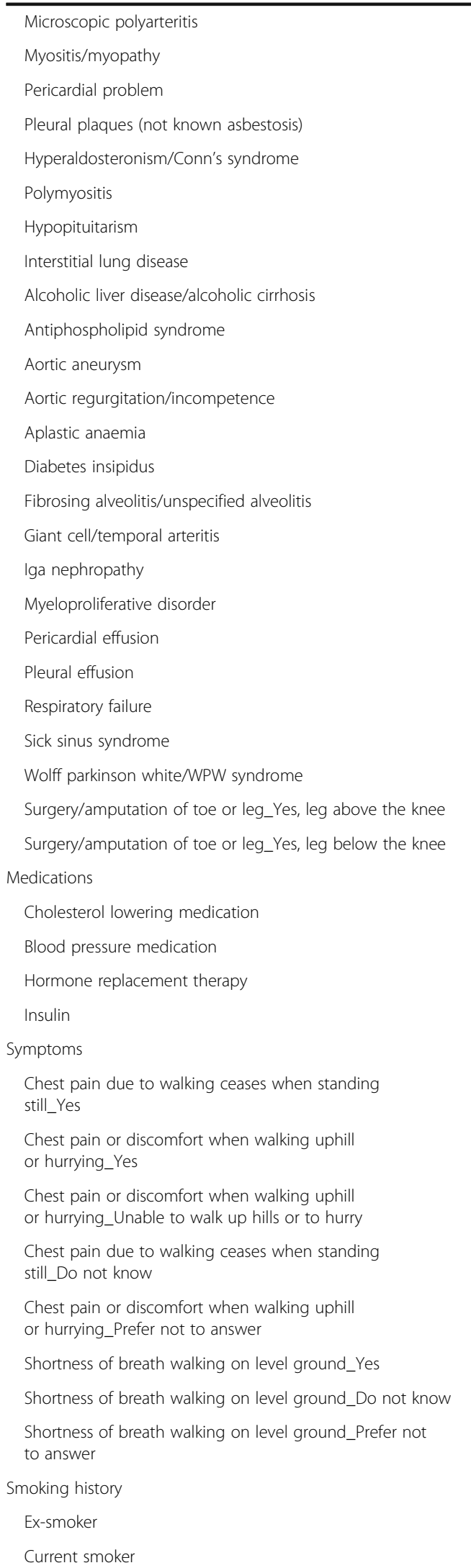

Table 11 Exclusion criteria (Continued)

\section{$1(0 \%)$ \\ $1(0 \%)$ \\ $1(0 \%)$ \\ $1(0 \%)$ \\ $1(0 \%)$ \\ $1(0 \%)$ \\ $1(0 \%)$ \\ $1(0 \%)$ \\ $1(0 \%)$ \\ $1(0 \%)$ \\ $1(0 \%)$ \\ $1(0 \%)$ \\ $1(0 \%)$ \\ $1(0 \%)$ \\ $1(0 \%)$ \\ $1(0 \%)$ \\ $1(0 \%)$ \\ $1(0 \%)$ \\ $1(0 \%)$ \\ $1(0 \%)$ \\ $1(0 \%)$ \\ $1(0 \%)$ \\ $1(0 \%)$ \\ $1(0 \%)$ \\ $1(0 \%)$}

$784(16 \%)$

$705(14 \%)$

331 (7\%)

$15(0 \%)$

264 (5\%)

$229(5 \%)$

$20(0 \%)$

$17(0 \%)$

$2(0 \%)$

$386(8 \%)$

$76(2 \%)$

$5(0 \%)$

1896 (38\%)

355 (7\%)
High body mass index

$B M I \geq 30$

$1158(23 \%)$

Ethnicity

Other ethnic group

$30(1 \%)$

Indian

$29(1 \%)$

Pakistani

$19(0 \%)$

Caribbean

$19(0 \%)$

Chinese

$17(0 \%)$

Prefer not to answer $\quad 17(0 \%)$

African

$16(0 \%)$

Any other mixed background $\quad 15(0 \%)$

Any other Asian background $\quad 12(0 \%)$

White and Black Caribbean $8(0 \%)$

White and Asian $\quad 7(0 \%)$

White and Black African 5 (0\%)

Bangladeshi $2(0 \%)$

Do not know $2(0 \%)$

Any other Black background $\quad 1(0 \%)$

Asian or Asian British $1(0 \%)$

N.B. Criteria listed are not mutually exclusive

\section{Appendix 2}

Table 12 Ventricular parameters stratified by gender

\begin{tabular}{llll}
\hline & All & Males & Females \\
\hline Number & 800 & 368 & 432 \\
LVEDV $(\mathrm{ml})$ & $143 \pm 34$ & $166 \pm 32$ & $124 \pm 21$ \\
LVESV $(\mathrm{ml})$ & $58 \pm 17$ & $69 \pm 16$ & $49 \pm 11$ \\
LVSV $(\mathrm{ml})$ & $85 \pm 20$ & $96 \pm 20$ & $75 \pm 14$ \\
LV mass $(\mathrm{g})$ & $85 \pm 24$ & $103 \pm 21$ & $70 \pm 13$ \\
indexed LVEDV $\left(\mathrm{ml} / \mathrm{m}^{2}\right)$ & $79 \pm 14$ & $85 \pm 15$ & $74 \pm 12$ \\
indexed LVESV $\left(\mathrm{ml} / \mathrm{m}^{2}\right)$ & $32 \pm 8$ & $36 \pm 8$ & $29 \pm 6$ \\
indexed LVSV $\left(\mathrm{ml} / \mathrm{m}^{2}\right)$ & $47 \pm 9$ & $49 \pm 10$ & $45 \pm 8$ \\
indexed LV mass $\left(\mathrm{g} / \mathrm{m}^{2}\right)$ & $47 \pm 10$ & $53 \pm 9$ & $42 \pm 7$ \\
LVEF $(\%)$ & $60 \pm 6$ & $58 \pm 5$ & $61 \pm 5$ \\
LV mass to Volume ratio $(\mathrm{g} / \mathrm{ml})$ & $0.60 \pm 0.11$ & $0.63 \pm 0.11$ & $0.57 \pm 0.11$ \\
RVEDV (ml) & $154 \pm 40$ & $182 \pm 36$ & $130 \pm 24$ \\
RVESV $(\mathrm{ml})$ & $69 \pm 24$ & $85 \pm 22$ & $55 \pm 15$ \\
RVSV $(\mathrm{ml})$ & $85 \pm 20$ & $97 \pm 20$ & $75 \pm 14$ \\
indexed RVEDV $\left(\mathrm{ml} / \mathrm{m}^{2}\right)$ & $85 \pm 17$ & $93 \pm 17$ & $77 \pm 13$ \\
indexed RVESV $\left(\mathrm{ml} / \mathrm{m}^{2}\right)$ & $38 \pm 11$ & $43 \pm 11$ & $33 \pm 9$ \\
indexed RVSV $\left(\mathrm{ml} / \mathrm{m}^{2}\right)$ & $47 \pm 9$ & $50 \pm 9$ & $45 \pm 8$ \\
RVEF $(\%)$ & $56 \pm 6$ & $54 \pm 6$ & $58 \pm 6$ \\
\hline
\end{tabular}

The data are presented in mean \pm SD. The independent sample t-test's $p$-value was $<0.0001$ for all parameters

$\mathrm{LV}$, left ventricle; RV, right ventricle; EDV, end-diastolic volume; ESV, end-systolic volume; SV, stroke volume; EF, ejection fraction; indexed, absolute values divided by body surface area 
Table 13 Atrial parameters stratified by gender

\begin{tabular}{llll}
\hline & All & Males & Females \\
\hline Number & 795 & 363 & 432 \\
Maximal LA volume (2Ch) (ml)* & $61 \pm 20$ & $66 \pm 20$ & $57 \pm 18$ \\
Maximal LA volume (4Ch) (ml)* & $74 \pm 22$ & $78 \pm 23$ & $70 \pm 21$ \\
Maximal LA volume (Biplane) (ml)* & $66 \pm 19$ & $71 \pm 19$ & $62 \pm 17$ \\
LA SV (Biplane) (ml)* & $40 \pm 11$ & $42 \pm 11$ & $34 \pm 10$ \\
indexed Maximal LA volume (2Ch) (ml) & $34 \pm 10$ & $40 \pm 12$ & $34 \pm 10$ \\
indexed Maximal LA volume (4Ch) (ml) & $41 \pm 12$ & $36 \pm 9$ & $42 \pm 12$ \\
indexed Maximal LA volume (Biplane) (ml) & $37 \pm 10$ & $22 \pm 6$ & $37 \pm 10$ \\
indexed LA SV (Biplane) (ml) & $22 \pm 6$ & $60 \pm 7$ & $22 \pm 6$ \\
LA EF (Biplane) (\%) & $60 \pm 7$ & $93 \pm 27$ & $61 \pm 7$ \\
Maximal RA volume (4Ch) (ml)* & $80 \pm 25$ & $38 \pm 14$ & $69 \pm 17$ \\
RA SV (4Ch) (ml)* & $35 \pm 13$ & $48 \pm 14$ & $32 \pm 10$ \\
indexed Maximal RA volume (4Ch) (ml)* & $44 \pm 12$ & $20 \pm 7$ & $41 \pm 10$ \\
indexed RA SV (4Ch) (ml) & $19 \pm 7$ & $41 \pm 9$ & $19 \pm 6$ \\
RA EF (4Ch) (\%)* & $44 \pm 10$ & & $46 \pm 9$
\end{tabular}

The data are presented in mean \pm SD. ${ }^{*} p$-value $<0.0001$

LA, left atrium; RA, right atrium; SV, stroke volume; $\mathrm{EF}$, ejection fraction; $2 \mathrm{Ch}$, two-chamber; $4 \mathrm{Ch}$, four-chamber; Biplane, derived from four-chamber and twochamber views; indexed, absolute values divided by body surface area

Table 14 Correlation table for ventricular parameters with age

\begin{tabular}{|c|c|c|c|c|}
\hline & \multicolumn{2}{|l|}{ Males } & \multicolumn{2}{|c|}{ Females } \\
\hline & $r^{a}$ & Level of significance & $r^{a}$ & Level of \\
\hline \multicolumn{5}{|l|}{ Significance } \\
\hline LVEDV & -0.19 & $* * * *$ & -0.19 & $* * * *$ \\
\hline LVESV & -0.14 & $* *$ & -0.16 & $* *$ \\
\hline LVSV & -0.18 & $* * * *$ & -0.16 & $* *$ \\
\hline LV mass & -0.13 & * & -0.04 & \\
\hline indexed LVEDV & -0.13 & * & -0.15 & $* *$ \\
\hline indexed LVESV & -0.09 & & -0.13 & * \\
\hline indexed LVSV & -0.12 & * & -0.12 & * \\
\hline indexed LV mass & -0.07 & & 0.01 & \\
\hline LVEF & -0.02 & & 0.03 & \\
\hline LV mass to volume ratio & 0.06 & & 0.14 & $* *$ \\
\hline RVEDV & -0.21 & $* * * *$ & -0.18 & $* * * *$ \\
\hline RVESV & -0.18 & $* * * *$ & -0.18 & $* * * *$ \\
\hline RVSV & -0.19 & $* * * *$ & -0.12 & * \\
\hline indexed RVEDV & -0.16 & $* *$ & -0.15 & $* *$ \\
\hline indexed RVESV & -0.14 & $* *$ & -0.16 & $* *$ \\
\hline indexed RVSV & -0.13 & * & -0.08 & \\
\hline RVEF & 0.06 & & 0.11 & * \\
\hline
\end{tabular}

${ }^{* * * *} p<0.001 ;{ }^{* * *} p<0.001 ;{ }^{* *} p<0.01 ;{ }^{*} p<0.05$

${ }^{\text {a }}$ Pearson correlation coefficient

LV, left ventricle; RV, right ventricle; EDV, end-diastolic volume; ESV, end-systolic volume; SV, stroke volume; EF, ejection fraction; indexed, absolute values divided by body surface area 
Table 15 Correlation table for atrial parameters with age

\begin{tabular}{|c|c|c|c|c|}
\hline & Males & & Female & \\
\hline & $r^{a}$ & Level of significance & $r^{a}$ & Level of significance \\
\hline Maximal LA volume (2Ch) & -0.11 & * & -0.11 & * \\
\hline Maximal LA volume (4Ch) & -0.1 & & -0.14 & ** \\
\hline Maximal LA volume (Biplane) & -0.11 & * & -0.14 & ** \\
\hline LA SV (Biplane) & -0.12 & * & -0.23 & **** \\
\hline indexed Maximal LA volume (2Ch) & -0.07 & & -0.08 & \\
\hline indexed Maximal LA volume (4Ch) & -0.05 & & -0.11 & * \\
\hline indexed Maximal LA volume (Biplane) & -0.06 & & -0.11 & * \\
\hline indexed LA SV (Biplane) & -0.07 & & -0.2 & **** \\
\hline LA EF (Biplane) & -0.01 & & -0.15 & ** \\
\hline Maximal RA volume (4Ch) & 0.01 & & 0 & \\
\hline RA SV (4Ch) & 0 & & -0.06 & \\
\hline indexed Maximal RA volume (4Ch) & 0.06 & & 0.04 & \\
\hline indexed RA SV (4Ch) & 0.04 & & -0.03 & \\
\hline RA EF (4Ch) & 0.01 & & -0.11 & * \\
\hline
\end{tabular}

**** $p<0.001 ;{ }^{* * *} p<0.001 ; * * 0<0.01 ;{ }^{*} p<0.05$

apearson correlation coefficient

LA, left atrium; RA, right atrium; SV, stroke volume; EF, ejection fraction; 2Ch, two-chamber; 4Ch, four-chamber; Biplane, derived from four-chamber and two-chamber views; indexed, absolute values divided by body surface area

\section{Appendix 3}
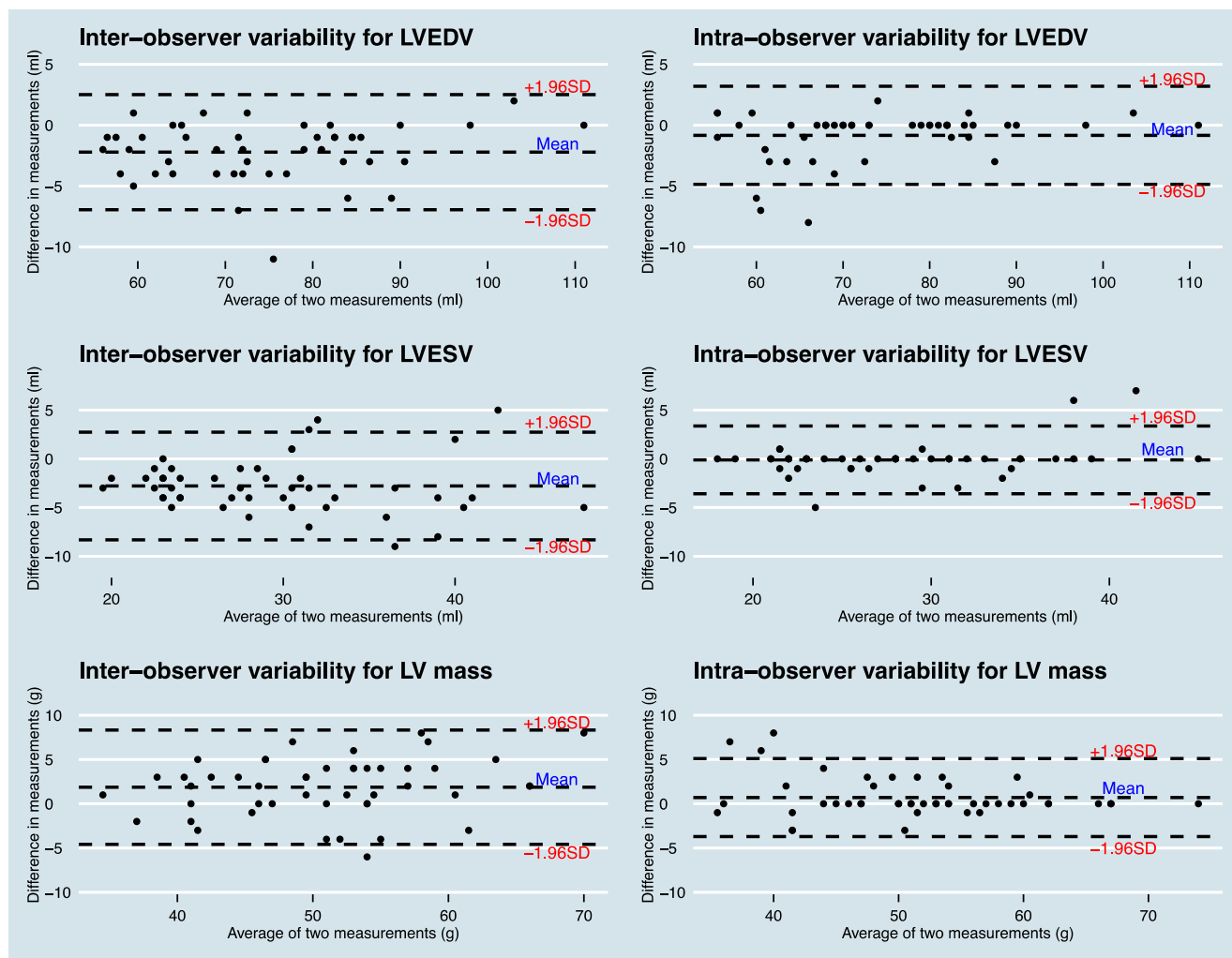

Fig. 3 Exemplar Bland-Altman plots for inter- and intra-observer variability of left ventricular parameters 

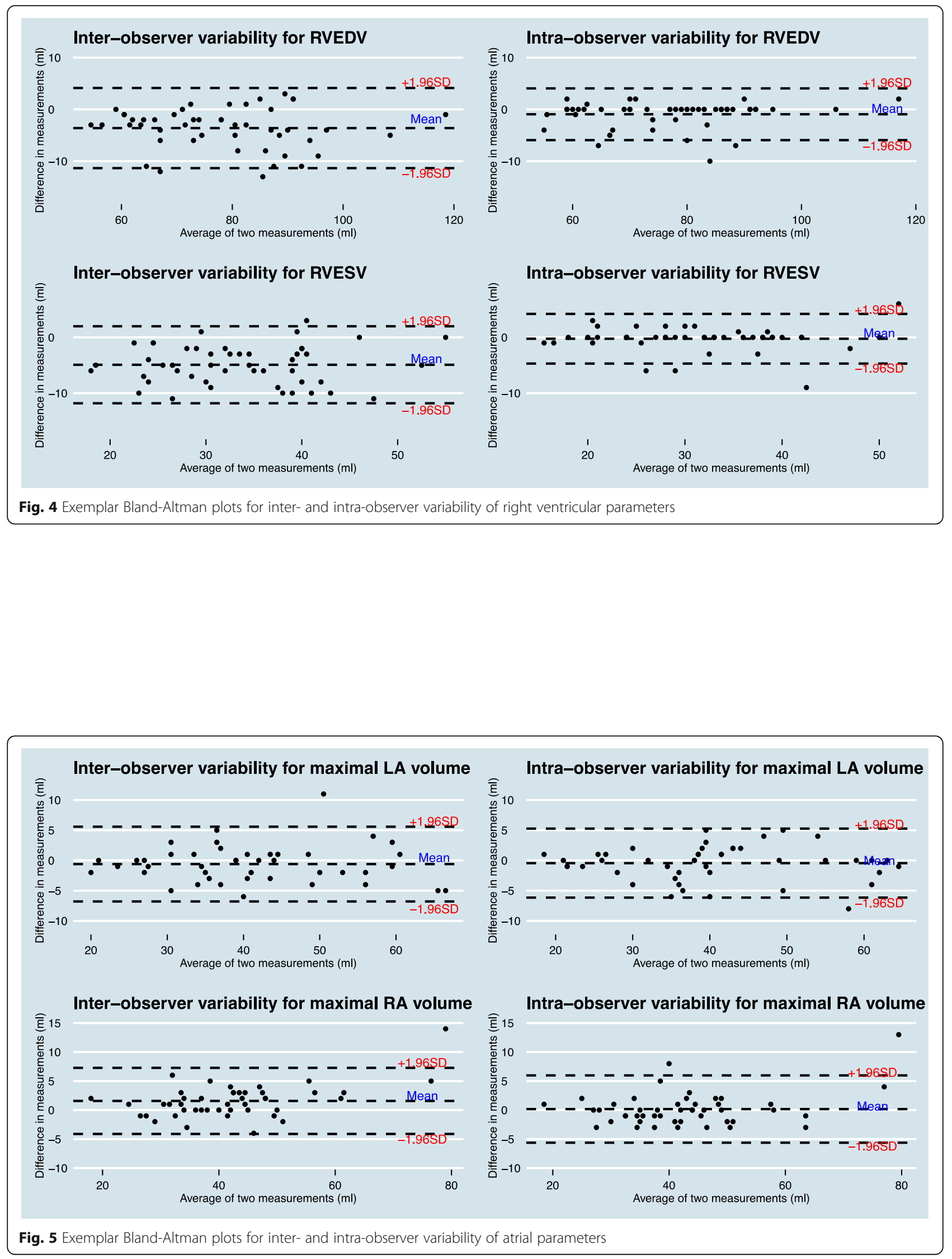


\section{Appendix 4}

\section{UK Biobank data}

UK Biobank data in a codified tabular format, received through our access application, was used to select the healthy cohort. Data was translated, using the data dictionary provided as part of the application and the coding tables available through the UK Biobank website, into a self-contained table which we used to perform the analysis. The data derived from the analysis of CMR studies were tested for gross errors such as nonphysiological values (e.g., end-systolic volume larger than end-diastolic volume) and were removed from the final dataset.

\section{Additional file}

Additional file 1: Supplementary materials. (PDF 475 kb)

\section{Abbreviations}

[b]SSFP: [Balanced] steady state free precession; BMI: Body mass index; BSA: Body surface area; CMR: Cardiovascular magnetic resonance; HLA: Horizontal long axis; ICC: Intra-class correlation coefficient; LA: Left atrium; LV: Left ventricle; LVOT: Left ventricular outflow tract; MESA: Multi-Ethnic Study of Atherosclerosis; RA: Right atrium; RV: Right ventricle; SD: Standard deviation; TE: Echo time; TR: Repetition time; VLA: Vertical long axis

\section{Acknowledgements}

Not applicable.

\section{Funding}

SEP was directly funded by the National Institute for Health Research Cardiovascular Biomedical Research Unit at Barts. SN and SKP are supported by the Oxford NIHR Biomedical Research Centre and the Oxford British Heart Foundation Centre of Research Excellence. SEP, SN and SKP acknowledge the British Heart Foundation (BHF) for funding the manual analysis to create a cardiovascular magnetic resonance imaging reference standard for the UK Biobank imaging resource in 5000 CMR scans (PG/14/89/31194).

\section{Availability of data and materials}

This research has been conducted using the UK Biobank resource (see Appendix 4). The raw data, the derived data, the analysis and results will be clearly annotated and returned to UK Biobank, which will then incorporate the returned data into the central repository. UK Biobank will make the data available to all bona fide researchers for all types of health-related research that is in the public interest, without preferential or exclusive access for any person. All researchers will be subject to the same application process and approval criteria as specified by UK Biobank. Please see UK Biobank website for the detailed access procedure (http://www.ukbiobank.ac.uk/register-apply/).

\section{Authors' contributions}

The study was conceived and designed by SEP, SP and SN. EL, JMJP, NA, MMS, KF, VC, YJK performed the image analysis. VC, NA and AL performed the final data analysis. MMS, NA and SEP drafted the manuscript, all authors commented on the manuscript and approved the final version of the manuscript.

\section{Competing interests}

SEP provides consultancy to Circle Cardiovascular Imaging Inc, Calgary, Canada. The other authors declare that they have no competing interests.

\section{Consent for publication}

All participants in this study gave written consent to participate and to publish as part of the UK Biobank recruitment process.
Ethics approval and consent to participate

UK Biobank's project has been approved by National Research Ethics Service North West (11/NW/0382).

\section{Author details}

${ }^{1}$ William Harvey Research Institute, NIHR Cardiovascular Biomedical Research Unit at Barts, Queen Mary University of London, Charterhouse Square, London EC1M 6BQ, UK. '2Division of Cardiovascular Medicine, Radcliffe Department of Medicine, University of Oxford, Level 6, West Wing, John Radcliffe Hospital, Headington, Oxford OX3 9DU, UK. ${ }^{3}$ Department of Radiology, Severance Hospital, Yonsei University College of Medicine, 50-1 Yonsei-ro, Seodaemun-gu, Seoul 03722, South Korea.

Received: 8 October 2016 Accepted: 14 January 2017

Published online: 03 February 2017

\section{References}

1. Maceira AM, Prasad SK, Khan M, Pennell DJ. Normalized left ventricular systolic and diastolic function by steady state free precession cardiovascular magnetic resonance. J Cardiovasc Magn Reson. 2006:8:417-26.

2. Hudsmith L, Petersen S, Francis J, Robson M, Neubauer S. Normal human left and right ventricular and left atrial dimensions using steady state free precession magnetic resonance imaging. J Cardiovasc Magn Reson. 2005;7:775-82.

3. Alfakih K, Plein S, Thiele H, Jones T, Ridgway JP, Sivananthan MU. Normal human left and right ventricular dimensions for MRI as assessed by turbo gradient echo and steady-state free precession imaging sequences. J Magn Reson Imaging. 2003;17:323-9.

4. Kawel-Boehm N, Maceira A, Valsangiacomo-Buechel ER, Vogel-Claussen J, Turkbey EB, Williams R, et al. Normal values for cardiovascular magnetic resonance in adults and children. J Cardiovasc Magn Reson BioMed Central. 2015;17:29.

5. Yeon SB, Salton CJ, Gona P, Chuang ML, Blease SJ, Han Y, et al. Impact of age, sex, and indexation method on MR left ventricular reference values in the Framingham Heart Study offspring cohort. J Magn Reson Imaging NIH Public Access. 2015;41:1038-45.

6. Foppa M, Arora G, Gona P, Ashrafi A, Salton CJ, Yeon SB, et al. Right ventricular volumes and systolic function by cardiac magnetic resonance and the impact of sex, age, and obesity in a longitudinally followed cohort free of pulmonary and cardiovascular disease. Circ Cardiovasc Imaging Lippincott Williams \& Wilkins. 2016;9:e003810.

7. Sudlow C, Gallacher J, Allen N, Beral V, Burton P, Danesh J, et al. UK Biobank: an open access resource for identifying the causes of a wide range of complex diseases of middle and old age. PLoS Med Public Library of Science. 2015;12:e1001779.

8. Petersen SE, Matthews PM, Bamberg F, Bluemke DA, Francis JM, Friedrich $M G$, et al. Imaging in population science: cardiovascular magnetic resonance in 100,000 participants of UK Biobank - rationale, challenges and approaches. J Cardiovasc Magn Reson. 2013;15:46.

9. Petersen SE, Matthews PM, Francis JM, Robson MD, Zemrak F, Boubertakh R, et al. UK Biobank's cardiovascular magnetic resonance protocol. J Cardiovasc Magn Reson BioMed Central Ltd. 2016;18:8.

10. Lang RM, Badano LP, Mor-Avi V, Afilalo J, Armstrong A, Ernande L, et al. Recommendations for cardiac chamber quantification by echocardiography in adults: an update from the American Society of Echocardiography and the European Association of Cardiovascular Imaging. J Am Soc Echocardiogr. 2015;28:1-39.e14

11. Carapella V, Jimenez-Ruiz E, Lukaschuk E, Aung N, Fung K, Paiva J, et al. Towards the semantic enrichment of free-text annotation of image quality assessment for UK Biobank cardiac Cine MRI scans. Lect Notes Comput Sci. 2016;238-48. 1.

12. Solberg HE. The theory of reference values Part 5. Statistical treatment of collected reference values. Determination of reference limits. J Clin Chem Clin Biochem Zeitschrift für Klin Chemie und Klin Biochem. 1983;21:749-60.

13. Du Bois D, Du Bois EF. A formula to estimate the approximate surface area if height and weight be known. Arch Intern Med. 1916;17:863-71.

14. Bland JM, Altman DG. Statistical methods for assessing agreement between two methods of clinical measurement. Lancet (London, England). 1986;1:307-10.

15. Hallgren KA. Computing inter-rater reliability for observational data: an overview and tutorial. Tutor Quant Methods Psychol NIH Public Access. 2012;8:23-34. 
16. R Core Team. R: A Language and Environment for Statistical Computing. Vienna; 2016.

17. Dweck MR, Joshi S, Murigu T, Gulati A, Alpendurada F, Jabbour A, et al. Left ventricular remodeling and hypertrophy in patients with aortic stenosis: insights from cardiovascular magnetic resonance. J Cardiovasc Magn Reson. 2012;14:50.

18. Sievers B, Kirchberg S, Franken U, Bakan A, Addo M, John-Puthenveettil B, et al. Determination of normal gender-specific left atrial dimensions by cardiovascular magnetic resonance imaging. J Cardiovasc Magn Reson. 2005;7:677-83.

19. Maceira AM, Cosín-Sales J, Roughton M, Prasad SK, Pennell DJ. Reference left atrial dimensions and volumes by steady state free precession cardiovascular magnetic resonance. J Cardiovasc Magn Reson. 2010;12:65.

20. Maceira AM, Cosín-Sales J, Roughton M, Prasad SK, Pennell DJ, Sanfilippo A, et al. Reference right atrial dimensions and volume estimation by steady state free precession cardiovascular magnetic resonance. J Cardiovasc Magn Reson BioMed Central. 2013:15:29.

21. Gandy SJ, Lambert M, Belch J, Cavin I, Crowe E, Littleford R, et al. 3T MR investigation of cardiac left ventricular structure and function in a UK population: The tayside screening for the prevention of cardiac events (TASCFORCE) study. J Magn Reson Imaging. 2016:44:1186-96.

22. Le Ven F, Bibeau K, De Larochellière É, Tizón-Marcos H, DeneaultBissonnette S, Pibarot P, et al. Cardiac morphology and function reference values derived froma large subset of healthy young Caucasian adults by magnetic resonance imaging. Eur Heart J Cardiovasc Imaging. 2016;17:98190.

23. Helge Erik Solberg DS. IFCC recommendation: the theory of reference values. Part 4. Control ofanalytical variation in the production, transfer and application of reference values. J Automat Chem Hindawi Publishing Corporation. 1991;13:231.

24. Lieb W, Xanthakis V, Sullivan LM, Aragam J, Pencina MJ, Larson MG, et al. Longitudinal tracking of left ventricular mass over the adult life course: clinical correlates of short- and long-term change in the framingham offspring study. Circulation American Heart Association Journals. 2009;1 19:3085-92.

25. Fuchs A, Mejdahl MR, Kühl JT, Stisen ZR, Nilsson EJP, Køber LV, et al. Normal values of left ventricular mass and cardiac chamber volumes assessed by 320-detector computed tomography angiography in the Copenhagen General Population Study. Eur Hear I Cardiovasc Imaging Oxford University Press. 2016;322:1561-6.

26. Chung AK, Das SR, Leonard D, Peshock RM, Kazi F, Abdullah SM, et al. Women have higher left ventricular ejection fractions than men independent of differences in left ventricular volume: the Dallas Heart Study. Circulation American Heart Association Journals. 2006;113:1597-604.

27. Natori S, Lai S, Finn JP, Gomes AS, Hundley WG, Jerosch-Herold M, et al. Cardiovascular Function in Multi-Ethnic Study of Atherosclerosis: Normal Values by Age, Sex, and Ethnicity. Am J Roentgenol. American Roentgen Ray Society; 2012.

28. Strait JB, Lakatta EG. Aging-associated cardiovascular changes and their relationship to heart failure. Heart Fail Clin NIH Public Access. 2012;8:143-64.

29. Schulman SP, Lakatta EG, Fleg JL, Lakatta L, Becker LC, Gerstenblith G. Age-related decline in left ventricular filling at rest and exercise. Am J Physiol. 1992;263:H1932-8.

30. Kitzman DW, Scholz DG, Hagen PT, Ilstrup DM, Edwards WD. Age-related changes in normal human hearts during the first 10 decades of life. Part II (maturity): a quantitative anatomic study of 765 specimens from subjects 20 to 99 years old. Mayo Clin Proc. 1988;63:137-46.

31. Margossian R, Schwartz ML, Prakash A, Wruck L, Hurwitz LM, Marcus E, et al. Comparison of echocardiographic and cardiac magnetic resonance imaging measurements of functional single ventricular volumes, mass, and ejection fraction (From the Pediatric Heart Network Multicenter Fontan CrossSectional Study). Am J Cardiol. 2010;104:419-28.

32. Teo KSL, Carbone A, Piantadosi C, Chew DP, Hammett CJK, Brown MA, et al Cardiac MRI assessment of left and right ventricular parameters in healthy Australian normal volunteers. Hear Lung Circ. 2008;17:313-7.

33. Rider OJ, Francis JM, Ali MK, Byrne J, Clarke K, Neubauer S, et al. Determinants of left ventricular mass in obesity; a cardiovascular magnetic resonance study. J Cardiovasc Magn Reson BioMed Central. 2009;11:9.

34. Rider OJ, Petersen SE, Francis JM, Ali MK, Hudsmith LE, Robinson MR, et al. Ventricular hypertrophy and cavity dilatation in relation to body mass index in women with uncomplicated obesity. Heart BMJ Publishing Group Ltd and British Cardiovascular Society. 2011;97:203-8.

35. Health and Social Care Information Centre. Statistics on Obesity, Physical Activity and Diet. 2016

\section{Submit your next manuscript to BioMed Central and we will help you at every step:}

- We accept pre-submission inquiries

- Our selector tool helps you to find the most relevant journal

- We provide round the clock customer support

- Convenient online submission

- Thorough peer review

- Inclusion in PubMed and all major indexing services

- Maximum visibility for your research

Submit your manuscript at www.biomedcentral.com/submit
Biomed Central 